\title{
A New Hybrid Method for China's Energy Supply Security Forecasting Based on ARIMA and XGBoost
}

\author{
Pin $\mathrm{Li}^{1,2}$ and Jin-Suo Zhang ${ }^{3, *(10}$ \\ 1 School of Safety Science and Engineering, Xi'an University of Science and Technology, Xi'an 710054, China; \\ lipin1012@126.com \\ 2 Research Center for Energy Economy and Management, Xi'an University of Science and Technology, \\ Xi'an 710054, China \\ 3 School of Economics and Management, Yan'an University, Yan'an 716000, China \\ * Correspondence: zjs@yau.edu.cn; Tel.: +86-133-8922-9988
}

Received: 26 May 2018; Accepted: 26 June 2018; Published: 27 June 2018

\begin{abstract}
Energy supply security is a significant part of China's security, directly influencing national security and economic and social sustainability. To ensure both China's present and the future energy supply, it is essential to evaluate and forecast the energy supply level. However, forecasting the energy supply security level is difficult because energy supply security is dynamic, many factors affect it and there is a lack of accurate and comprehensive data. Therefore, based on previous studies and according to the characteristics of energy supply and the social development of China, first, the authors apply a comprehensive evaluation method to quantify the energy supply security. Second, based on the ARIMA-XGBoost hybrid model, the authors create two novel approaches for forecasting the energy supply security level of China. The authors find that: (1) energy supply security is dynamic, and green development has become the theme of China's energy development. The energy industry urgently needs to provide more high-quality ecological energy products to meet the people's desire for a beautiful ecological environment; (2) since the mean absolute percentage errors are below $4.5 \%$ when forecasting the energy supply security indicators, the ARIMA-XGBoost hybrid model is more accurate for forecasting China's energy supply security level and (3) the security level of China's energy supply has developed periodic features; the ESSI can improve by about 0.2 every five years, but, due to the low starting point and multiple types of constraints, it is difficult to reach the safety level in a short time.
\end{abstract}

Keywords: energy supply security index; ARIMA; XGBoost; Shannon entropy; hybrid model

\section{Introduction}

Energy is the most basic source of power for the development of human society, a constraint condition for economic development and the progress of civilization, and an important basis for the national economy to achieve sustainable development and national security. The energy supply and security have a bearing on the overall development of a country's economy, which is crucial for a country's prosperity and development, improvement of people's life, and its long-term social stability. The increase in clean, affordable and safe energy is a top priority for the current energy supply with the reduction of fossil fuels and the increase of $\mathrm{CO}_{2}$ in the atmosphere. The global energy demand will continue to grow in the future. It is expected that by 2040, total global energy demand will increase by one third, and China and India are the two driving forces [1]. As a large energy producer and consumer country, China's energy supply security is an important part of energy security. Following a long period of development, China's energy supply has entered a "new era" where China's energy development has achieved remarkable results: a continuous slowdown in the total energy demand 
growth, accelerated transformation of the energy supply structure, and obvious energy efficiency enhancement. Thus, a comprehensive and multi-level energy supply system has been formed for coal, electricity, oil, natural gas, new energy, and renewable energy.

Although China has made great achievements in energy development, the country's energy development is changing dynamically. New features continue to emerge during the development process, and these are accompanied by new problems that put more pressure on the energy supply. First, profound changes are taking place in the connotation of energy development. China's energy development plan, in the past, was centered on the idea that "the people can use energy". During the new era, the goal of China's energy development plan is to improve the efficiency and quality of energy development and achieve more comprehensive and sustainable development. Second, green development has become the theme of energy development. Since the Nineteenth National Congress of the Communist Party of China, green energy development has become a yardstick for measuring the level of construction of social-ecological civilization and an inevitable requirement for building an energy system of clean, low-carbon emissions that are safe and efficient. Only by practicing the concept of green development can China optimize the energy structure, guarantee the security of the energy supply, promote the construction of ecological civilization, and effectively resolve the contradiction between the people's ever-growing needs for a better life and unbalanced and inadequate development in the new era. Third, the constraints imposed on the energy supply by resources and the environment have intensified. China has pledged to the international community that the country's carbon dioxide emissions will peak by 2030, or perhaps earlier, and that non-fossil energy will make up approximately $20 \%$ of its primary energy consumption [2]. China will achieve the goal of a fundamental improvement in its ecological environment and the realization of a beautiful China by 2035 . Fourth, the changes in people's energy demands have placed higher demands on the energy supply. During the new era, the energy needs of the people are changing from "use of energy" to "use of good energy" and "use of green energy". The request for quality and quantity of energy supply will also increase, and the demand for energy services will become more modern. Green energy supply and green development have become the basic requirements for the energy supply of the contemporary world. The energy industry must, both urgently and continuously, carry out scientific and technological innovation to optimize the energy supply structure and provide more high-quality ecological energy products to meet the people's desire for a beautiful ecological environment. Presently, the global energy market is in a transitional period, and the world is struggling to meet the dual challenges of energy supply and reducing carbon emissions; China is no exception and should take a positive role in the global energy transition.

Currently, China's energy supply is still coal-dominated. The total supply is large, but the effective supply is insufficient. The supply and demand are misaligned. The contradiction between energy supply and the public's demand for green energy is still prominent. Although China's energy science and technology has made great progress, it still lags far behind other advanced countries. Thus, can China's energy be successfully transformed? When can it be transformed? When can the energy supply meet the needs of the people? Can the contradiction between energy supply and demand be solved? Ergo, when can it be solved? To solve these problems, it is necessary to evaluate and forecast the energy supply.

\section{Literature Review}

Recently, there have been many predictive modelling methods related to energy. These are mainly divided into two types of models: the first type are traditional forecasting models, such as regression models, time series models, econometrics models, and the Auto Regressive Integrated Moving Average (ARIMA) model; the second type consists of soft computing models, like genetic algorithms, neural networks, fuzzy logic (FL), and the support vector machine (SVM) $[3,4]$. The most commonly used traditional statistical model is the ARIMA model, which harnesses historical data for a forecasting model and can capture training data to set linear relationships [5]. Coalla [6] used 
an ARIMA model in 1999 to forecast future energy production and consumption in the Asturias, Conejo et al. [7] employed an ARIMA to forecast mainland Spain's electricity market prices, Ediger [8] used regression, ARIMA and Seasonal time series ARIMA (SARIMA) models to forecast Turkish fossil fuel production, and Pappas and Erdogdu et al. [9,10] used an ARIMA model to forecast electricity consumption, thus proving that this model is more efficient than other time-series models. Overall, studies have found that the ARIMA can produce good modeling and forecasting results for energy production and/or energy consumption; however, most studies used single models to forecast single variables.

While the statistical models and artificial techniques have developed, models that employ artificial intelligence are now being developed as forecasting models to optimize the established models' parameters and to build hybrid models with superior performance. Newly developed artificial intelligence and machine learning models such as the artificial neural network (ANN), FL, and support vector machines (SVM) are now being widely used for energy forecasting [11]. To forecast Taiwan's energy consumption, Pao [12] developed two new kinds of hybrid nonlinear models based on a linear model and ANN to account for any heteroscedasticity in the model inputs. Tan [13] then proposed an innovative price forecasting method based on a wavelet transform combined with Generalized Auto Regressive Conditional Heteroscedastic (GARCH) and ARIMA models to examine the Spanish electricity market and the PJM INT., L.L.C. (PJM) electricity market in the Eastern United States. To develop a more reliable forecasting model, Kavousi-Fard [14] developed a new hybrid model combining ARIMA and Support Vector Regression (SVR) with the cuckoo search algorithm method and applied it to examine Fars Electrical Power Company's empirical peak load data in Iran. Yan [15] used a novel hybrid mid-term electricity market clearing price (MCP) forecasting model that combined both the SVM and Auto Regressive Moving Average with External input (ARMAX) models and demonstrated its improved forecasting accuracy. Using an integrated approach combined an emotional learning based fuzzy inference system and ANN with an adaptive neuro-fuzzy inference system, Azadeh [16] proposed a hybrid forecasting model and used it to forecast natural gas consumption forecasting. Yuan [17] employed the ARIMA and Grey Model $(1,1)$ model for China's primary energy consumption. To forecast wind speed, Niu [18] developed a novel hybrid forecasting model, combing empirical mode decomposition (EMD) and the general regression neural network (GRNN) optimized by the fruit fly optimization algorithm (FOA) to forecast wind speed.

The American scholar Chen [19] proposed a new deep learning model in 2014 named XGBoost, which is widely used by data scientists and has achieved state-of-the-art results in many areas due to its general scalability. Lei [20] used six machine learning approaches to develop the prediction models, and the XGBoost classification model achieved the most accurate qualitative predictions. Torres-Barrán [21] applied a Gradient Boosted Regression model, a Random Forest Regression (RFR) model, and Extreme Gradient Boosting model to global and local wind energy forecasting and a solar radiation problem, with the results indicating that both methods were better than SVR for the solar radiation problem. Guangye [22] built a short-term power load XGBoost model with multi-information fusion for power load prediction with the results showing that the XGBoost forecasting model has advantages over random forest, Bayesian, and k-Nearest Neighbors models in terms of speed and prediction accuracy.

To conclude, there are many models for energy forecasting. The authors obtain some rules from these models, as follows: (1) Vertically from the time series, predictive methods are in transition from regression to artificial intelligence approaches, from machine learning to deep learning; (2) Predictive research methods are transitioning from a single model to combined models, with a great deal of current research having been focused on innovative hybrid models that integrate single-prediction models to provide advanced forecasting; (3) Regarding the point of research objectives, nearly all the research has been focused on energy demand, and research concerning energy supply has not been reported so far. Forecasting energy supply security is difficult, mainly due to two reasons: First and foremost, energy supply security is dynamic, many factors affect it, and it is difficult to 
quantify the energy supply security level for lack of accurate and comprehensive data. Second, because the energy supply system has more than one index, the forecast difficulty is increased; statistical forecasting methods need normal data, and large data sets indicate trends or seasonal data patterns, which are usually insufficient or noisy. Therefore, selecting a reasonable forecasting model is critical. As discussed, compared to other prediction models, the ARIMA models require less data, have fewer coefficients, and tend to be more accurate when integrated with other models. Unfortunately, as the ARIMA residuals have nonlinear structures [23], the ARIMA models' approximation for complex nonlinear problems might be inadequate; however, using data processing and data mining analysis technology for the error correction codes could lead to improved performances [24]; for example, as the XGBoost model is scalable in all scenarios and has rapid speed and high accuracy [19] it can be used to forecast the ARIMA residuals. Thus, the authors forecast China's energy supply security level using an ARIMA-XGBoost hybrid model. Section 3 defines China's energy supply security level, describes the proposed indicators that influence energy supply security in China and evaluates the energy supply security level of China by means of a comprehensive evaluation method. Section 4 , based on Section 3, proposes a novel ARIMA-XGBoost hybrid model and gives two forecasting approaches for China's energy supply security. Section 5 presents the study results and discussion, and Section 6 states the conclusions.

\section{Determining Energy Supply Security}

Energy supply security is affected greatly by many uncertain factors, such as energy demand, energy resource reserves, energy efficiency, energy technology, energy price, development cost, exchange rate, and interest rate $[25,26]$. Since it is contextual and dynamic in nature, it is difficult to quantify. Energy security has been given different definitions in different periods according to research background, subjects, and sample choices, with some research developing various index systems and assessment methods. The authors have put forward a new definition for energy supply security for China, conceptualized energy supply security in the four dimensions of availability, affordability, environment, and energy technology and efficiency, as well as calculated the energy supply security index (ESSI) by aggregation.

\subsection{Definition of Energy Supply Security}

Energy supply security is crucial to all countries. Over the years, scholars have carried out extensive research on energy security, and most scholars regard energy supply as the core of energy security research. The most common definition for energy security is obtaining an adequate energy supply at a reasonable price. This definition has received great attention from research institutions and scholars such as the International Energy Agency (IEA) [27,28] and the Asia Pacific Energy Research Center [29]. According to this definition, many scholars have carried out a lot of research on the energy security issue (Yergin [30], Van der Linde [31], Sovacool [32,33], Winzer [34]). However, Von [35] pointed out that this definition has become less salient for policy formation as energy markets have become more globally diverse, therefore, there are many energy security elements that need to be accounted for in addition to the traditional supply-side viewpoint such as environment, technology, social and cultural factors and more. Ang assessed 104 studies from 2001 to 2014 and found that availability, affordability, and energy efficiency were the key focus areas [36]. Since climate change issues and air pollution damage have become of greater concern, the environmental sustainability of energy systems has become a key objective for secure energy futures [37-39]. Energy supply security and energy sustainability are not in conflict. Especially in China, highly polluting coal is the main energy source, bringing about difficulty and safety risks to the economical society for sustainable development. Sustainability of energy supply should be paid more attention by the country and society. Among them, environmental sustainability is the basic premise of sustainable energy supply. Radovanovic [40] points out that the newly proposed energy security concept should include environmental and social aspects, that is sustainability. Since energy security definitions change at 
different economic development stages, it has become necessary to periodically revise the energy supply security definition to show the changes in priorities or the newly arising threats. China's energy industry has recently entered a new era whereby energy supplies are demanded to provide consumers with high-quality products and excellent service to meet people's ever-growing needs for a beautiful eco-environment. Consequently, combined with the current situation of China's energy supply and sustainable development requirements, the authors believe that energy supply security is not just one aspect of energy security and that the energy supply security system should be a dynamic system that not only needs to provide a reliable and adequate energy supply at reasonable prices, but it also should have sustainability; the energy it supplies will not have a negative impact on society and the environment in the course of consumption, be aligned with current economic development models, and be coordinated with environmental protection measures. According to this definition and comparison between previous studies and the present study as shown in Table 1, basically, a concrete definition for energy supply security can be generalized into the following four aspects:

(1) Availability

Providing regional energy resources are developed and energy supply diversification promoted, adequate and stable energy supply security systems can be assured. As fossil fuels are phased out, the next cheapest fuel is used first [41], and after this source is depleted, the other fossil fuel or renewable energy resource needs to be available to guarantee continuing and adequate energy supplies. Alternatively, another fossil fuel or renewable energy source could replace more expensive or less acceptable fuels [42]. Moreover, energy reserves and diverse energy resources are fundamental to continuing energy supply security [43].

(2) Affordability

Reliable, adequate energy supplies at reasonable prices are required for energy supply security, which means that supplies need to be affordable to ensure prices remain reasonable. These reliable, adequate energy supplies also need to be able to resist the risk of shocks from energy import dependency, as this can give rise to economic vulnerability. Any disturbances in any of the supply stages could increase prices, disruptions in the downstream stages could influence individual energy users on the micro level and affect the national economies on the macro level [44]. Regarding energy research, vulnerability has generally referred to the negative effects associated with energy import dependence [45]. Therefore, due to China's dependence on imported crude oil increasing, this paper includes a consideration of the economic vulnerability from crude oil import dependence.

\section{(3) Environment}

Energy and the environment are closely connected as fossil fuel combustion has a direct relationship with environmental pollution, and even environmentally clean energy resources can damage the environment [46]. Other environmental risks include forest inundation caused by hydropower projects and leaks and spills of oil during the exploration or transportation of crude oil. The European Commission places special emphasis on environmental issues and sustainability of energy security [47]. Since environmental protection has become a major international concern, it has also become a major focus for building a more beautiful China. Therefore, to ensure that energy supplies are safer and more reliable, a spatial structure that is related to both resource conservation and environmental protection is necessary.

\section{(4) Energy Technology and Efficiency}

This aspect is related to either obtaining the same services or the same output with less energy input. Since a country's energy efficiency reflects its energy technology development levels, energy efficiency improvements can significantly reduce energy consumption. Therefore, to develop multilevel energy supplies, advanced energy technological systems and practices are important [48-50] in reducing overall energy needs and improving energy supply security. While promoting energy efficiency and reducing energy use is the key policy for tackling energy security problems [51,52], good infrastructure must be considered a prerequisite for stable energy supplies and "economic energy security". 
Table 1. Comparison between previous studies and present study.

\begin{tabular}{|c|c|c|c|c|c|c|c|c|c|c|}
\hline \multirow{2}{*}{ No. } & \multirow{2}{*}{ Source } & \multirow{2}{*}{ Themes } & \multirow{2}{*}{ Dimension } & \multirow{2}{*}{$\begin{array}{c}\text { No. of } \\
\text { Countries }\end{array}$} & \multirow{2}{*}{ Time Frame } & \multirow{2}{*}{$\begin{array}{l}\text { No. of } \\
\text { Indicator }\end{array}$} & \multicolumn{3}{|c|}{ Assessment Method } & \multirow{2}{*}{$\begin{array}{r}\text { Provide } \\
\text { Rank }\end{array}$} \\
\hline & & & & & & & Normalization & Weighting & Model & \\
\hline 1 & Coq [53] & Energy supply security & Oil, Gas, Coal & 24 & 1 & 3 & - & - & Aggregation & $\sqrt{ }$ \\
\hline 2 & Sovacool [32] & Energy security, Energy supply & $\begin{array}{l}\text { Availability, Affordability, Technology development, } \\
\text { Sustainability and regulation }\end{array}$ & 10 & 5 & 20 & - & - & Subjective scoring & $\sqrt{ }$ \\
\hline 3 & Malavika [54] & Energy security, Energy supply & $\begin{array}{l}\text { Security of energy supply, Climate change, Energy } \\
\text { efficiency, New energy technologies, Self-sufficiency } \\
\text { and trade. }\end{array}$ & 1 & - & 16 & - & - & Questionnaire survey & $\sqrt{ }$ \\
\hline 4 & Hippel [55] & Energy security, Energy supply & Security of supply, Economic & 1 & - & 29 & - & - & Forum discussion & - \\
\hline 5 & Sovacool [56] & Energy security, Energy supply & $\begin{array}{l}\text { Availability, Affordability, Technology development, } \\
\text { Sustainablity }\end{array}$ & 1 & - & 320 & - & - & $\begin{array}{l}\text { Questionnaire survey, } \\
\text { Literature review }\end{array}$ & - \\
\hline 6 & Ang [36] & Energy security, Energy supply & Economic, Energy supply chain, Environment & 1 & 5 & 22 & - & $\begin{array}{l}\text { Subjective } \\
\text { Weight }\end{array}$ & Aggregation & $\sqrt{ }$ \\
\hline 7 & Geng [57] & Energy supply security & $\begin{array}{l}\text { Availability, Affordability, Energy technologies and } \\
\text { energy efficiency, Energy resource reserves }\end{array}$ & 1 & 8 & 7 & Min-Max & - & Aggregation & $\checkmark$ \\
\hline 8 & Zhang [58] & Coal security & Safe, Green and Efficient. & - & - & 22 & Min-Max & AHP & Aggregation & $\sqrt{ }$ \\
\hline 9 & $\operatorname{Ren}[59]$ & Energy security & Availability, Accessibility, Affordability, Acceptability & 1 & 1 & 24 & - & - & Fuzzy DEMATEL & - \\
\hline 10 & Brown [60] & Energy security, Energy supply & Availability, Affordability, Efficiency, Environment & 22 & 40 & 10 & - & - & Aggregation & $\sqrt{ }$ \\
\hline 11 & $\begin{array}{l}\text { Ren and } \\
\text { Sovacool [61] }\end{array}$ & Energy security & Availability, Affordability, Accessibility Acceptability & 1 & 1 & 10 & & AHP & TOPSIS & - \\
\hline 12 & Narula [62] & Energy security, Energy supply & Availability, Affordability, Acceptability, Efficiency & 1 & 3 & 16 & Min-Max & $\begin{array}{l}\text { Subjective } \\
\text { Weight }\end{array}$ & $\begin{array}{l}\text { Multi-objective decision } \\
\text { model }\end{array}$ & - \\
\hline 13 & Vivoda V [63] & Energy security, Energy supply & $\begin{array}{l}\text { Energy supply, Demand management, Efficiency, } \\
\text { Economic, ethnological }\end{array}$ & 10 & 1 & 44 & - & - & - & - \\
\hline 14 & Lucas [64] & Energy security, Energy supply & Energy supply, Environment & 22 & 1 & 12 & - & - & Econometrics & - \\
\hline 15 & Erahman [65] & Energy security & $\begin{array}{l}\text { Availability, Affordability, Accessibility, Acceptability } \\
\text { and efficiency. }\end{array}$ & 71 & 6 & 14 & Min-Max & PCA & Aggregation & $\checkmark$ \\
\hline 16 & Li [66] & Energy security & Vulnerability, Efficiency, Sustainability & 4 & 13 & 9 & - & $\begin{array}{c}\text { Equal } \\
\text { weight }\end{array}$ & Aggregation & $\sqrt{ }$ \\
\hline 17 & Cohen [67] & Energy security, Energy supply & Diversification & 27 & - & - & - & - & Aggregation & $\checkmark$ \\
\hline 18 & Pavlović [68] & Energy supply security & $\begin{array}{l}\text { Energy Import Dependency Index, Energy Intensity, } \\
\text { Gross Inland Consumption ... }\end{array}$ & 1 & 15 & 6 & - & $\begin{array}{c}\text { Subjective } \\
\text { Weight }\end{array}$ & Aggregation & $\sqrt{ }$ \\
\hline 19 & Duenas [69] & Energy supply security & Strategic energy policy, Adequacy, Firmness, Security & 1 & 54 & - & - & - & $\begin{array}{l}\text { Coordination } \\
\text { scheduling model }\end{array}$ & $\sqrt{ }$ \\
\hline 20 & Mohsin [70] & Energy security, supply risk & $\begin{array}{l}\text { Supply risk, Infrastructure risk, Market risk; } \\
\text { Transportation risk; Dependence risk }\end{array}$ & 7 & 5 & 11 & - & - & DEA & $\sqrt{ }$ \\
\hline 21 & Castro [71] & Security of supply & $\begin{array}{l}\text { The loss of load duration, the loss of load occurrence } \\
\text { the energy not supplied }\end{array}$ & 1 & 2 & 6 & - & - & $\begin{array}{l}\text { Monte Carlo } \\
\text { Simulation (MCS) }\end{array}$ & - \\
\hline
\end{tabular}




\subsection{Evaluation of Energy Supply Security}

The ESSI has often been used to assess energy supply security levels. Based on ESSI indicators' perceived importance, each of the indicators is given a certain weight, after which a proper aggregation method is used to combine them to form a composite energy security index. Using this approach, several organizations and national energy agencies have developed energy security indexes in the past, for example, the "Index of U.S. Energy Security Risk" and the "International Index of Energy Security Risk" [72,73]. This paper, therefore, develops an ESSI for China.

\subsubsection{Energy Supply Security Index Construction}

Energy supply security systems are complex systems with many factors. Based on China's energy and resource features, energy security indicators are used to gauge the energy supply security. It is not possible to measure energy supply security with a simple indicator, instead, it has been studied often using a basket of indicators (or metrics) based on a specific framework for the various dimensions; however, the number of indicators should not exceed 20 [36]. Considering China's current energy supply situation and the multiple risks it is facing, the energy supply security evaluation indexes for China for the four risk dimensions of energy availability, affordability, environment, and energy technology and efficiency were determined based on research interviews, a focused workshop, an extensive literature review, and data availability, as shown in Table 2. The first-grade indexes reflect changes in certain aspects of the energy supply security system, and the second-grade indexes reflect changes in the factors that influence the energy supply security system; therefore, the proposed framework uses 12 indicators to evaluate and forecast China's energy supply security.

Table 2. Evaluation indexes of China's energy supply security.

\begin{tabular}{|c|c|c|c|c|}
\hline $\begin{array}{l}\text { First Grade } \\
\text { Indexes }\end{array}$ & $\begin{array}{l}\text { Second Grade } \\
\text { Indexes }\end{array}$ & Equation & Variable Description & Indicator Source \\
\hline \multirow{3}{*}{ Availability } & $\begin{array}{c}\text { Reserve and } \\
\text { production ratio }\end{array}$ & $\sum_{i=1}^{m} r_{i *} p_{i}$ & $\begin{array}{l}r_{i} \text { - Reserve and production } \\
\text { ratio of energy } i, p_{i} \text {-Proportion } \\
\text { of energy } i \text { produced in energy } \\
\text { sources' production }\end{array}$ & {$[32,56,57,65,74,75]$} \\
\hline & $\begin{array}{c}\text { Production } \\
\text { diversity index }\end{array}$ & $\sqrt{\sum_{i=1}^{m} p_{i}^{2}}$ & $\begin{array}{l}p_{i} \text {-Proportion of energy } i \\
\text { produced in energy } \\
\text { sources' production }\end{array}$ & {$[36,55,56,63,64,74,76]$} \\
\hline & Energy dependence & $\frac{Q_{e i t}}{Q_{e s t}}$ & $\begin{array}{l}\text { Qeit-Energy import quantum, } \\
\text { Qest-TPES }\end{array}$ & {$[32,56,59,66,72,74]$} \\
\hline Affordability & Energy price index & - & $\begin{array}{l}\text { Purchase price index of } \\
\text { fuel and power by } \\
\text { industrial producers }\end{array}$ & {$[36,56,59,60,72,74]$} \\
\hline \multirow{4}{*}{ Environment } & Waste water emissions & $\longrightarrow$ & Total waste water emissions & {$[32,36,55,56,59,76]$} \\
\hline & $\mathrm{SO}_{2}$ emissions & - & Total sulfur dioxide emissions & {$[36,55,60,63,66,72,76]$} \\
\hline & NOx emissions & $\longrightarrow$ & Total NOx emissions & {$[32,36,55,56,60,63,64,66,72,76]$} \\
\hline & $\mathrm{CO}_{2}$ emissions & $\longrightarrow$ & Total carbon dioxide emissions & {$[55,56,64,72]$} \\
\hline
\end{tabular}


Table 2. Cont.

\begin{tabular}{|c|c|c|c|c|}
\hline $\begin{array}{l}\text { First Grade } \\
\text { Indexes }\end{array}$ & $\begin{array}{l}\text { Second Grade } \\
\text { Indexes }\end{array}$ & Equation & Variable Description & Indicator Source \\
\hline \multirow{3}{*}{$\begin{array}{l}\text { Energy technology } \\
\text { and efficiency }\end{array}$} & $\begin{array}{l}\text { Clean power } \\
\text { generation }\end{array}$ & & $\begin{array}{l}\text { The proportion of clean power } \\
\text { generation in } \\
\text { power-generation capacity }\end{array}$ & {$[32,36,59,65,66,72]$} \\
\hline & $\begin{array}{l}\text { Domestic } \\
\text { infrastructure }\end{array}$ & & $\begin{array}{l}\text { Investment in fixed assets of } \\
\text { energy industry }\end{array}$ & {$[44,77]$} \\
\hline & Energy efficiency & $\mathrm{GDP} / \mathrm{Ec}$ & Ec-Total energy consumption & {$[32,36,56,57,60,63-66,78]$} \\
\hline
\end{tabular}

Data sources: Main data sources include the China Statistics Yearbook (2006-2017), the National Bureau of Statistics of The People's Republic of China, and the Wind Database. The reserve and production ratios and production diversity index were derived from the China Statistics Yearbook. The energy dependence, energy price index, and the economic vulnerability index were derived from the Wind Database. The $\mathrm{CO}_{2}$ emissions, $\mathrm{SO}_{2}$ emissions, waste water emissions, NOx emissions, clean power generation, domestic infrastructure, and energy efficiency were derived from the National Bureau of Statistics of The People's Republic of China and the Wind Database. The primary energy sources were coal, crude oil, natural gas, and other new and renewable energy production.

\subsubsection{Indicator Normalization}

Considering the differences in each indicator, the original data should be normalized. Referring to Narula et al. $[79,80]$, in this paper, indicators in the energy supply system are normalized by the Min-Max Normalization Method. Indicators can be categorized into two types: positive indicators and negative indicators, where the first type are indicators that have a positive influence on ESSI, and the second are those that have a negative influence. Regarding positive indicators, the bigger the better while, regarding negative indicators, the smaller the better. When the indicator is positive, it can be calculated using Equation (1), and when the indicator is negative, it can be calculated using Equation (2):

$$
\begin{aligned}
& y_{i t}^{\prime}=\frac{y_{i t}-\min \left(y_{i t}\right)}{\max \left(y_{i t}\right)-\min \left(y_{i t}\right)} \\
& y_{i t}^{\prime}=\frac{\max \left(y_{i t}\right)-y_{i t}}{\max \left(y_{i t}\right)-\min \left(y_{i t}\right)}
\end{aligned}
$$

where $y_{i t}$ is the value of indicator for $i$ in the year $t, \max \left(y_{i t}\right)$ is the maximum values of the $i$ th indicator, $\min \left(y_{i t}\right)$ is the minimum values of the ith indicator, $y_{i t}^{\prime}$ is the normalized value of $y_{i t}$.

\subsubsection{Weighting and Aggregation}

Several methods have been suggested in energy security literature for weighting the indicators, such as the Principal Component Analysis, Equal Weights, Subjective Weight Allocation, and Analytic Hierarchy Process and Entropy Weight. Having tried some of these methods, considering various constraints such as availability and practicality of data, it was found that the Entropy Weight Method based on Shannon's entropy [81] was the most appropriate for the ESSI. Shannon's entropy is a concept of measurement of information uncertainty based on probability theory. It can be expressed as follows:

Step 1: The decision matrix $Y=\left\{y_{i t}^{\prime}, t=1,2, \ldots, n ; i=1,2, \ldots, m\right\}$ is normalized for each criterion $\mathrm{C}_{i}(i=1,2, \ldots, m)$. The normalized values $s_{i t}$ are calculated by Equation (3):

$$
s_{i t}=\frac{y_{i t}^{\prime}}{\sum_{t=1}^{n} y_{i t}^{\prime}}
$$

Step 2: The entropy $H_{i}$ for each criterion $C_{i}$ is calculated using Equation (4):

$$
H_{i}=-k \sum_{t=1}^{n} s_{i t} \ln \left(s_{i t}\right)
$$

$k$ is a constant, let $k=\frac{1}{\ln (n)}, \alpha_{i} \geq 0$ 
Step 3: The degree of divergence $D I V_{i}$ for the intrinsic information in each criterion $C_{i}$ is calculated using Equation (5):

$$
D I V_{i}=1-H_{i}
$$

Step 4: The entropy weight $w_{i}$ for each criterion $C_{i}$ is calculated using Equation (6):

$$
w_{i}=\frac{D I V_{i}}{\sum_{i=1}^{m} D I V_{i}}
$$

Once the weight was calculated, in reference to previous studies (Cohen [67], Ang [72]), aggregation methods were used to construct the ESSI:

$$
\operatorname{ESSI}_{t}=\sum_{i=1}^{m}\left(y_{i t}^{\prime} * w_{i}\right)
$$

where $w_{i}$ is the weight assigned to indicator $y_{i}$, and there are $m$ indicators.

\subsubsection{Evaluation Criteria}

The ESSI reflects the level of energy supply security of a country or region, and its value range is $[0,1]$. Referring to Liu [82], and in accordance with the step length of 0.2 , the corresponding security level of energy supply security was divided into five Grades, as shown in Table 3.

Table 3. Energy supply security level table.

\begin{tabular}{cccl}
\hline Number & Security Grade & Score Range & \multicolumn{1}{c}{ Basic Characteristics } \\
\hline 1 & I & $0.8-1$ & There were a few unsafe factors, and overall it was in a security state \\
2 & II & $0.6-0.8$ & $\begin{array}{l}\text { There were some unsafe factors, but overall it was in a basic security state } \\
\text { There were many unsafe factors and an overall weak security state } \\
4\end{array}$ \\
III & $0.4-0.6$ & $\begin{array}{l}\text { The safety factor had either been close to or exceeded half and overall } \\
\text { was not in a safe state }\end{array}$ \\
5 & IV & $0.2-0.4$ & $\begin{array}{l}\text { There were mainly unsafe factors and overall it was in a serious state } \\
\text { of insecurity }\end{array}$ \\
\hline
\end{tabular}

\section{Hybrid Forecasting Method for China's Energy Supply Security}

\subsection{Principles and Processes for Forecasting}

The authors propose ensemble based ARIMA-XGBoost hybrid models to forecast China's energy supply security. Extending previous research by Zhang [83] and Barak [23], in the first pattern, a time series is forecast using the ARIMA model, after which the ARIMA residuals are forecast using the XGBoost model, then, final forecasting results for each time series are achieved from the sum of the ARIMA and XGBoost models. Two different approaches are creatively developed to forecast China's energy supply security level, both of which advance energy security theory (as shown in Figure 1). 


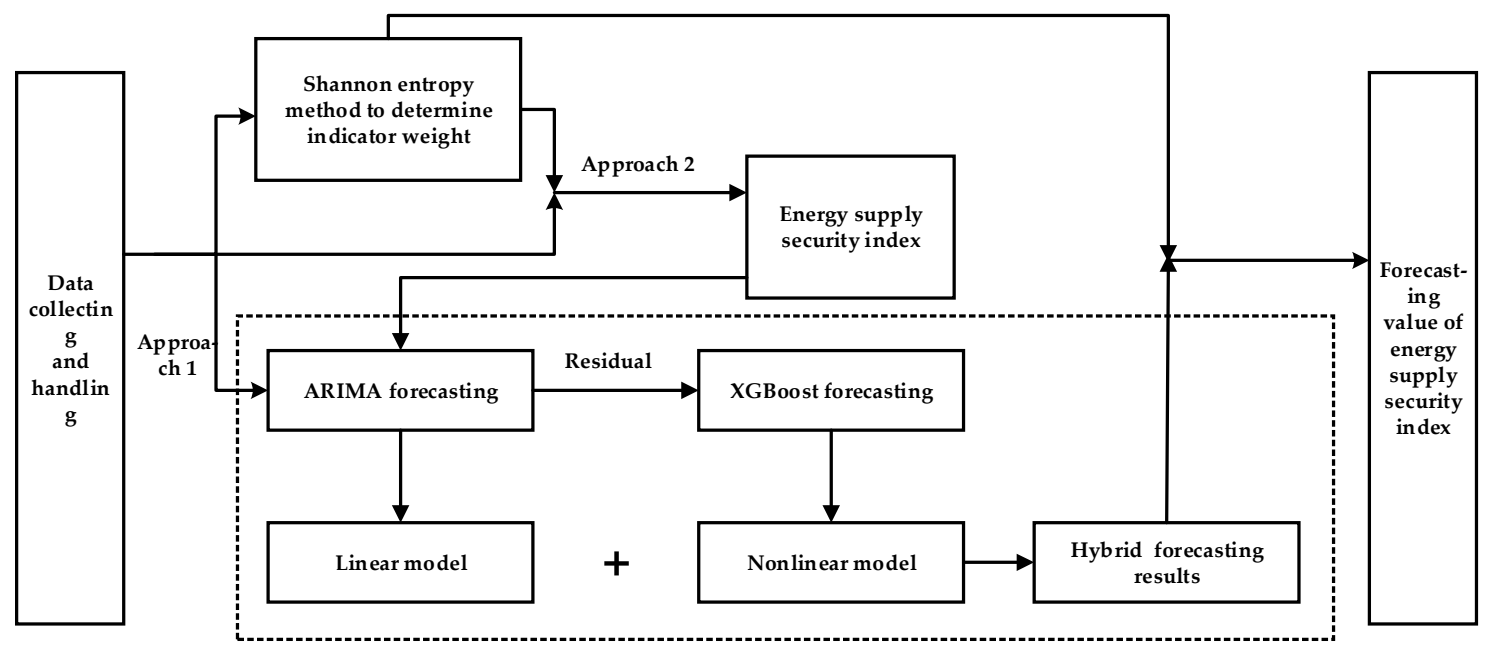

Figure 1. Hybrid forecasting principle for China's energy supply security.

(1) Approach 1: Calculate the Forecast ESSI* by Weighting the Forecast Index Value. This Task Consists of the Following Steps:

Step 1: Forecasting by Linear Model

First, time series are constructed for each energy supply security indicator $y_{i t}$, and a stationarity inspection and data randomness test conducted. Let the ARIMA model be the linear component and $y_{i t}^{*}$ denote the forecasting value of each index. Then, the residuals from the linear model contain only a nonlinear relationship. Let $e_{i t}$ refer to the residual at Time $t$ from the linear model; then:

$$
e_{i t}=y_{i t}-y_{i t}^{*}
$$

\section{Step 2: Forecasting by Nonlinear Model}

Residuals are very important for diagnosing the adequacy of linear models. When the linear correlation structure remains in the residual, the linear model is not sufficient, however, residual analyses are unable to detect nonlinear patterns in data and, currently, there is no general diagnostic statistics for nonlinear autocorrelation. Consequently, even if a model has passed the diagnostic examination, the model might not be sufficient because the nonlinear relationship has not been modeled properly. Any significant nonlinear pattern in the residuals of the ARIMA indicates its limitations. Via modeling of the ARIMA residuals using XGBoost, therefore, these nonlinear relationships can be revealed. Taking the residuals from the previous window as the input variable, the relative optimal regression model of XGBoost was achieved and the forecasting value of the residuals in each index $\hat{e}_{i t}$ determined.

Step 3: Forecasting by Hybrid Model

The combination of the ARIMA and XGBoost models results in a hybrid forest model:

$$
y_{p t}=y_{i t}^{*}+\hat{e}_{i t}
$$

Step 4: Forecasting Energy Supply Security

Weight each indicator's forecasting value $y_{p t}$ and its weight $w_{i}$, then get the ESSI forecasting value ESSI I from Equation (10), which is the first approach:

$$
\operatorname{ESSI}_{1}^{*}=\sum_{i=1}^{m}\left(y_{p t} * w_{i}\right)
$$


First, the authors calculate the ESSI within the sample period using Equation (7), which was a new time series for each indicator, and then, according to the computational Equation (8) and Equation (9) in Approach 1 obtain the forecasting value of the ESSI: ESSI $I_{2}^{*}$.

\subsection{Forecasting Method}

\subsubsection{ARIMA Model}

The authors use the ARIMA model to forecast each time series. First, the ARIMA model is predefined as [84]:

$$
y_{t}=\sum_{\theta=1}^{p} \alpha_{i} y_{t-i}+\sum_{j=1}^{q} \beta_{j} \varepsilon_{t-j}+\varepsilon_{t}
$$

where $\varepsilon_{t}$ represents the uncorrelated random noise of each time series, $\alpha_{i}(\theta=1,2, \ldots, p)$ and $\beta_{j}(j=1,2$, $\ldots, q)$ are the $\mathrm{m} \times \mathrm{m}$ coefficient matrices of the multivariate (MV) ARIMA model. The construction of the ARIMA model consists of four Steps [85]: Step 1, model identification, Step 2, parameter estimation, Step 3, model recognition, and Step 4, model verification and forecasting.

\subsubsection{XGBoost Model}

XGBoost is a scalable machine learning system used for tree boosting. XGBoost scalability is derived from several important systems and algorithm optimization, including a new tree learning algorithm for processing sparse data and a reasonable weighted quantile sketch process which allows the processing of instance weights in approximate tree learning. Quicker model exploration is possible as the parallel and distributed computing ensures faster learning. More importantly, XGBoost leverages off-core computing to enable data scientists to process hundreds of millions of examples on the desktop; therefore, it has been widely used for such forecasts such as store sales predictions, hazard risk prediction, and electricity load forecasting [86-88].The most important reason for the success of XGBoost has been that it is scalable in all scenarios.

Inspired by the above idea, the authors model the energy supply security prediction score of each $\hat{e}_{i}$, given the input $x_{i}$, using the following functional form:

$$
\hat{e}_{i}=\sum_{k=1}^{K} f_{k}\left(x_{i}\right) f_{k} \in \wp
$$

where the notation $K$ is the number of functions, and $\wp$ is the space that contains the function of the area partition and the score of each function. Formally, it is assumed that $\wp$ represents a set of regression trees. Regarding this model, it introduces the functions as parameters, allowing the authors to find the functions $f_{k} \in \wp$ that fit the data well when the model is trained and, therefore automatically can find the corresponding regions.

To learn the set of functions used in the model, the authors define the following regularized objective function as:

$$
\mathrm{Obj}=\sum_{i=1}^{n} l\left(e_{i}, \hat{e_{i}}\right)+\sum_{k=1}^{K} \Omega\left(f_{k}\right), f_{k} \in \wp
$$

where $l\left(e_{i}, \hat{e_{i}}\right)$ is a differentiable convex loss function measuring the difference between the prediction $\hat{e_{i}}$ and the target $e_{i,}$, and the second term, $\Omega$, measures the complexity of the model (the feature functions) to avoid over fitting. An important fact about Equation (13) is that the goal is regularized; that is, complicated models are penalized. Therefore, under this objective function, the model of a simple predictive function is selected as the best model.

Since the model contains functions as parameters, to find the solution it is not possible to use traditional optimization methods directly in the Euclidean space. Instead, additional training of the model is required: At each iteration $t$, the algorithm first searches the function space $\wp$ to identify a 
new function $f_{k}$, which can optimize the target function and add it to the set. Let $\hat{e}_{i}{ }^{(t)}$ be the prediction of the $i^{\text {th }}$ instance at the $t$ th iteration then, the authors need to find $f_{k}$ to optimize the following goals:

$$
\begin{aligned}
\text { Objective } & =\sum_{i=1}^{n} l\left(e_{i} \hat{e}_{i}^{(t)}\right)+\sum_{k=1}^{K} \Omega\left(f_{k}\right) \\
& =\sum_{i=1}^{n} l\left(e_{i}, \hat{e}_{i}^{(t-1)}+f_{t}\left(x_{i}\right)\right)+\sum_{k=1}^{K} \Omega\left(f_{k}\right)
\end{aligned}
$$

Using this objective the authors must add the best function to have an improvement in the model. Generally, because the above target is still difficult to optimize, the authors use the two-order Taylor expansion to approximate the target:

$$
\mathrm{Obj}^{(t)} \approx \sum_{i=1}^{n}\left[l\left(e_{i}, \hat{e}_{i}^{(t-1)}\right)+g_{i} f_{t}\left(x_{i}\right)+\frac{1}{2} h_{i} f_{t}^{2}\left(x_{i}\right)\right]+\sum_{k=1}^{K} \Omega\left(f_{k}\right)
$$

where $g_{i}=\partial_{\hat{e}^{(t-1)}} l\left(e_{i}, \hat{e}_{i}{ }^{(t-1)}\right)$ and $h_{i}=\partial_{\hat{e}^{(t-1)}}^{2} l\left(e_{i}, \hat{e}_{i}{ }^{(t-1)}\right)$. The constant terms can be removed to get the following approximate objective in Step $t$ :

$$
\mathrm{Obj}^{(t)} \approx \sum_{i=1}^{n}\left[g_{i} f_{t}\left(x_{i}\right)+\frac{1}{2} h_{i} f_{t}^{2}\left(x_{i}\right)\right]+\Omega\left(f_{t}\right)
$$

Define the mapping $\mathrm{q}: R^{d} \rightarrow\{1,2, \ldots, T\}$ that maps the input to the index of the region, and a vector $\omega$, which represents the score of each region, whose function is:

$$
\begin{gathered}
f_{t}(x)=\omega_{q(x)} \\
\omega \in R^{T}, \mathrm{q}: R^{d} \rightarrow\{1,2, \ldots, T\}
\end{gathered}
$$

There is a regression tree in this function class, for which q represents the decision tree structure on $x_{i}$ so, if needed, other forms of $\mathrm{q}$ also can be chosen to apply previous knowledge to the areas of interest. The authors also need to define the function complexity of $\Omega$ in the following way:

$$
\Omega(f)_{t}=\frac{1}{2} \lambda \sum_{j=1}^{T} \omega_{j}^{2}+\gamma T
$$

This regularization term penalizes the sum of the number of regions and the squared score for each region because learning too many regions and allocating too large scores to the leaves might lead to overfitting of the model and impairing its accuracy. The authors have also introduced $\gamma$ and $\lambda$ as two parameters to ensure balance. Define $I_{j}=\left\{i \mid q\left(x_{i}=j\right)\right\}$ as a set of instances of region $j$. Then, Equation (16) can be rewritten as shown below:

$$
\begin{aligned}
\mathrm{Obj}^{(t)} & =\sum_{i=1}^{n}\left[g_{i} \omega_{q\left(x_{i}\right)}+\frac{1}{2} h_{i} \omega_{q\left(x_{i}\right)}^{2}\right]+\gamma T+\frac{1}{2} \lambda \sum_{j=1}^{T} \omega_{j}^{2} \\
& \left.=\sum_{j=1}^{T}\left[\left(\sum_{i \in I_{j}} g_{i}\right) \omega_{j}+\frac{1}{2}\left(\sum_{i \in I_{j}} h_{i}\right)+\lambda\right) \omega_{j}^{2}\right]+\gamma T
\end{aligned}
$$

Now, the goal is the sum of the $\mathrm{T}$ independent two power functions of elements in $\mathrm{W}$. Since it is assumed that regional division, $q(x)$, is fixed, the optimal weight $\omega_{j}^{*}$ for region $j$ can be obtained as follows:

$$
\begin{gathered}
\omega_{j}^{*}=-\frac{\sum_{i \in I_{j}} g_{i}}{\sum_{i \in I_{j}} h_{i}+\lambda} \\
\text { Objective }=-\frac{1}{2} \sum_{j=1}^{T} \frac{\left(\sum_{i \in I_{j}} g_{i}\right)^{2}}{\sum_{i \in I_{j}} h_{i}+\lambda}+\gamma T
\end{gathered}
$$

The authors use the objective function in Equation (21) to determine a good structure. Since there might be an infinite number of alternatives in the tree structure, the authors have adopted a greedy 
algorithm in practical applications. Let $I_{L}$ and $I_{R}$ be the instance sets for the left and right nodes and $I=I_{L} \cup I_{R}$, then the gain in the loss reduction from introducing the split is calculated by:

$$
\text { Gain }=\frac{1}{2}\left[\frac{\left(\sum_{i \in I_{L}} g_{i}\right)^{2}}{\sum_{i \in I_{L}} h_{i}+\lambda}+\frac{\left(\sum_{i \in I_{R}} g_{i}\right)^{2}}{\sum_{i \in I_{R}} h_{i}+\lambda}-\frac{\left(\sum_{i \in I} g_{i}\right)^{2}}{\sum_{i \in I} h_{i}+\lambda}\right]-\gamma
$$

\section{Results and Discussion}

\subsection{Determination of Optimal Hybrid ARIMA-XGBoost Model}

Optimal hybrid ARIMA-XGBoost patterns are obtained according to the methods in Section 4. First, the accuracy of the ARIMA model and its error stability are selected. The best model is based on the mean absolute error. Since there are too many indicators, only the best ARIMA model of each indicator in Table 4 is shown. Then, a combination of the linear ARIMA model and the appropriate nonlinear XGBoost model is obtained according to Equations (9) and (12). The data are divided into training and test sets; $70 \%$ of the data is used as training set and the remaining $30 \%$ is used as test set. All the computations required for this paper have been carried out on the MATLAB 2017 workstation by preparing proper MATLAB routines.

Table 4. The best ARIMA(p, d, q) model of each indicator.

\begin{tabular}{cccc}
\hline Indicator & Optimal ARIMA Parameters & Indicator & Optimal ARIMA Parameters \\
\hline $\mathrm{y}_{1}$ & $\operatorname{ARIMA}(12,3,6)$ & $\mathrm{y}_{7}$ & $\operatorname{ARIMA}(12,3,6)$ \\
$\mathrm{y}_{2}$ & $\operatorname{ARIMA}(11,2,1)$ & $\mathrm{y}_{8}$ & $\operatorname{ARIMA}(10,2,11)$ \\
$\mathrm{y}_{3}$ & $\operatorname{ARIMA}(1,2,1)$ & $\mathrm{y}_{9}$ & $\operatorname{ARIMA}(11,2,8)$ \\
$\mathrm{y}_{4}$ & $\operatorname{ARIMA}(12,1,1)$ & $\mathrm{y}_{10}$ & $\operatorname{ARIMA}(9,1,1)$ \\
$\mathrm{y}_{5}$ & $\operatorname{ARIMA}(11,1,8)$ & $\mathrm{y}_{11}$ & $\operatorname{ARIMA}(10,2,2)$ \\
$\mathrm{y}_{6}$ & $\operatorname{ARIMA}(7,2,4)$ & $\mathrm{y}_{12}$ & $\operatorname{ARIMA}(11,2,1)$ \\
ESSI & $\operatorname{ARIMA}(10,2,1)$ & & \\
\hline
\end{tabular}

\subsection{Dimensional Forecasting Results}

Considering that the ESSI is composed of many indicators, the authors first forecast each indicator. The predicted value and dynamic evolutionary trends for each indicator of energy supply security are shown in Figures 2-13. According to the predicted results of each indicator by the ARIMA single model and the ARIMA-XGBoost hybrid model, all the single and hybrid models have highly accurate forecasting results because the mean absolute percentage forecast error are below $4.5 \%$. The forecasting results are grouped into the dimensions of availability, affordability, environment, and energy technology and efficiency.

\subsubsection{Availability Forecasting}

(1) Reserve and Production Ratio: Figure 2 shows China's energy reserve and production ratio dropped quickly, at an average of $12.28 \%$ a year, before 2011 and remained in a stable condition after 2011. However, after 2016 a slight drop has been predicted until 2021. Since the Chinese government had not paid much attention to the coal recovery rate before 2011, the coefficient of mining is lower. Following that, the Chinese government has taken various measures to ensure the energy reserve and production ratio. Taking China's Shenhua Group as an example: this coal mine adopts an eight-meter high mining face and, since each working face can recover more than 1.2 million tons in 48 months, the coal recovery rate is up to $98 \%$ in 2017 . Meanwhile, major breakthroughs in China were made in several key technologies such as coal-to-liquids, coal-to-methanol, and methanol-to-light-olefins. 


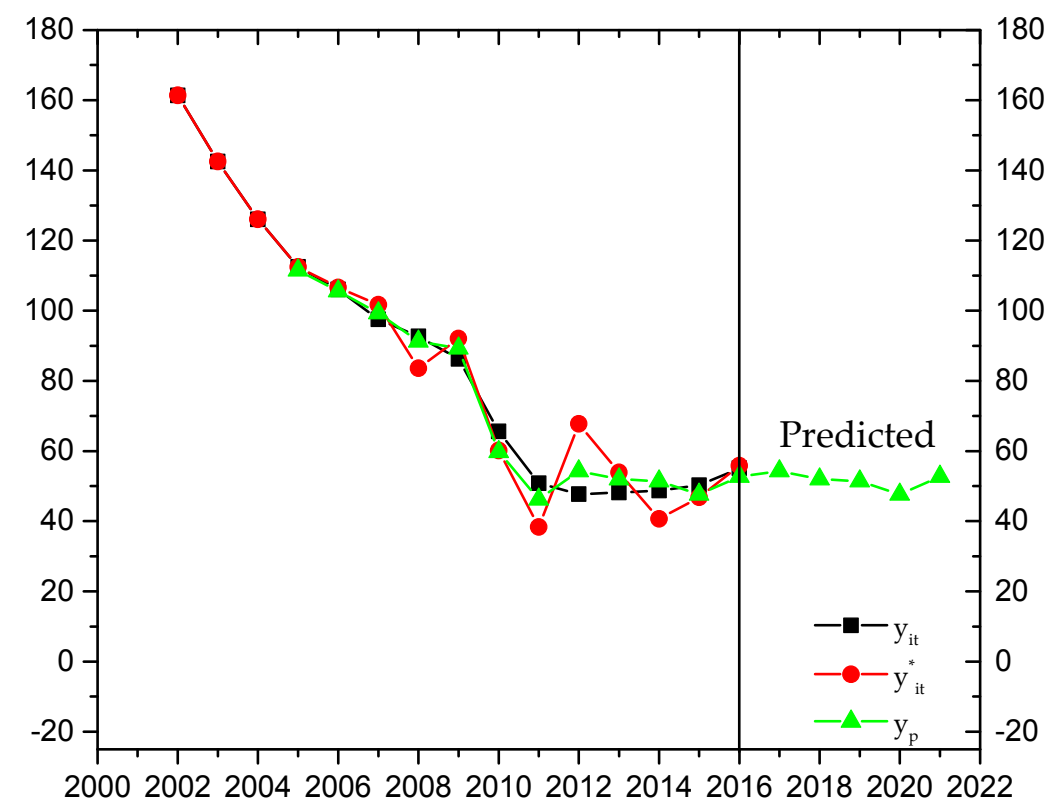

Figure 2. Reserve and production ratio.

(2) Production Diversity Index: Figure 3 shows the variation of production diversity results were relatively stable before 2010 but increased notably after that. Forecasting results show a rapid improvement trend in production diversity during the time between 2017-2021. China has paid attention to the development of non-fossil energy production in recent years. The IEA has pointed out that China spends up to 1320 billion Yuan on energy system construction in 2017, which is larger than the amount spent by the US and the European Union combined. During the same year, China's onshore wind power represented 35 percent of the global total, and the wind power average utilization was up to $1948 \mathrm{~h}$, a rise of $203 \mathrm{~h}$ from a year earlier. However, compared with the developed countries in the world, China's energy production diversity is still relatively low; three-quarters of EU countries have higher production diversity than this level.

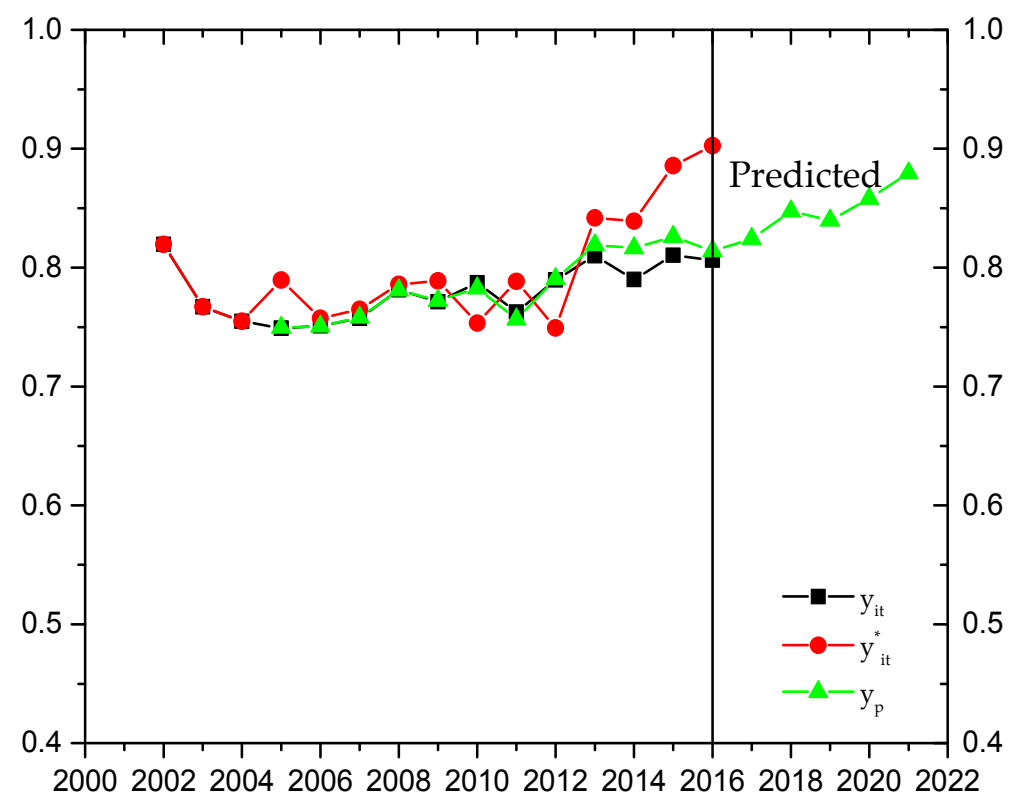

Figure 3. Production diversity index 
(3) Energy Dependence: Figure 4 demonstrates that China's energy dependence is increasing continuously and, since 2012, it has been maintained at a level above $15 \%$. Since China is a country with relatively low natural resources per capita, and energy efficiency is low, the main energy sources are highly dependent on foreign countries. During the past 10 years, the dependence of foreign oil was the most serious, rising from $39.5 \%$ in 2005 to $67.4 \%$ in 2017. China's oil supply system will remain sustainable for at most 180 days [89] if crude oil imports are interrupted. The dependence on natural gas has the most significant increase; it was 39\% in 2017, compared with $-6.4 \% 10$ years ago. China's resource endowment determines that China's energy dependence on foreign countries will continue to increase over the next five years. It is expected that by 2021, China's foreign energy dependence will reach $23.5 \%$.

Figures 2-4 display the increase of productivity might contribute to a slight decrease in the reserve and production ratio and slow the increase in energy dependence, as can be seen from the forecast values of indicators in the availability dimension. Overall, in the next five years, China's energy supply will remain stable, production diversity will be continuously improved, and the growth of energy dependence will slow down, all of which will contribute to a gradual increase in energy supply availability.

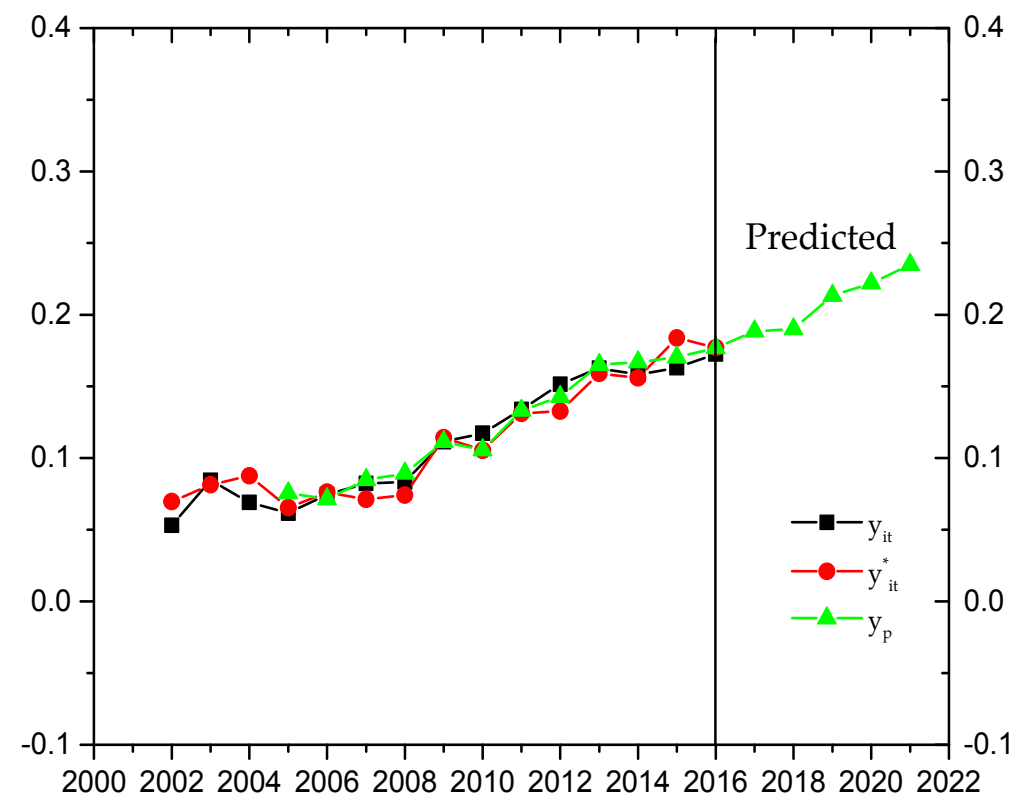

Figure 4. Energy dependence

\subsubsection{Affordability Forecasting}

(1) Energy Price Index: Figure 5 shows that China's energy price fluctuates greatly, mainly due to the different characteristics of Chinese market environments. Forecasting results show that from 2017 to 2021, China's energy price will continue to improve, but will not exceed or approach the recorded historical highest price. Since China's economy is moving into the "new normal", the comprehensive cost of utilizing new energy sources have been decreased significantly and oil reserves have reached the average level of the IEA. Thus, with the implementation of the price policy, the affordability of the energy price will be enhanced. 


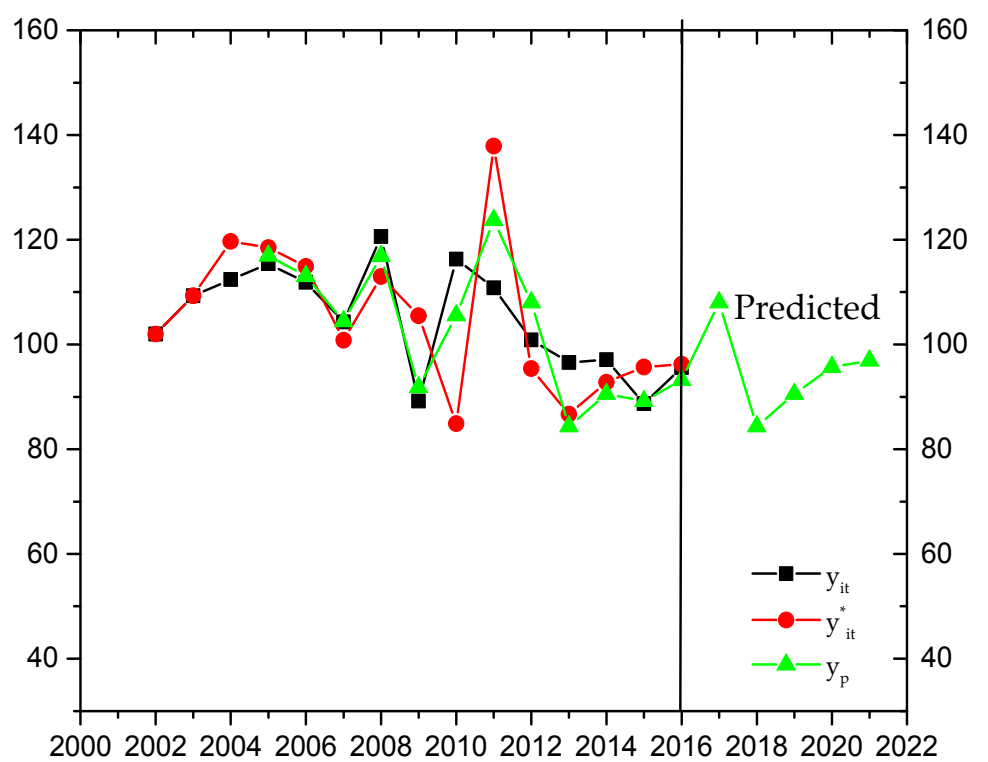

Figure 5. Energy price index

(2) The Economic Vulnerability Index: Figure 6 shows China's economic vulnerability index had a general "M" shaped trend from 2001 to 2016. The economic vulnerability index is higher before 2011, which indicates the negative effect of dependence on energy imports. Forecasting results show that, with the increase in energy diversity and the implementation of strategies to delay the growth of oil consumption, China's capacity to resist either the rise of, or sharp fluctuations in, oil prices will gradually increase, and the negative effect of dependence on energy imports will decrease.

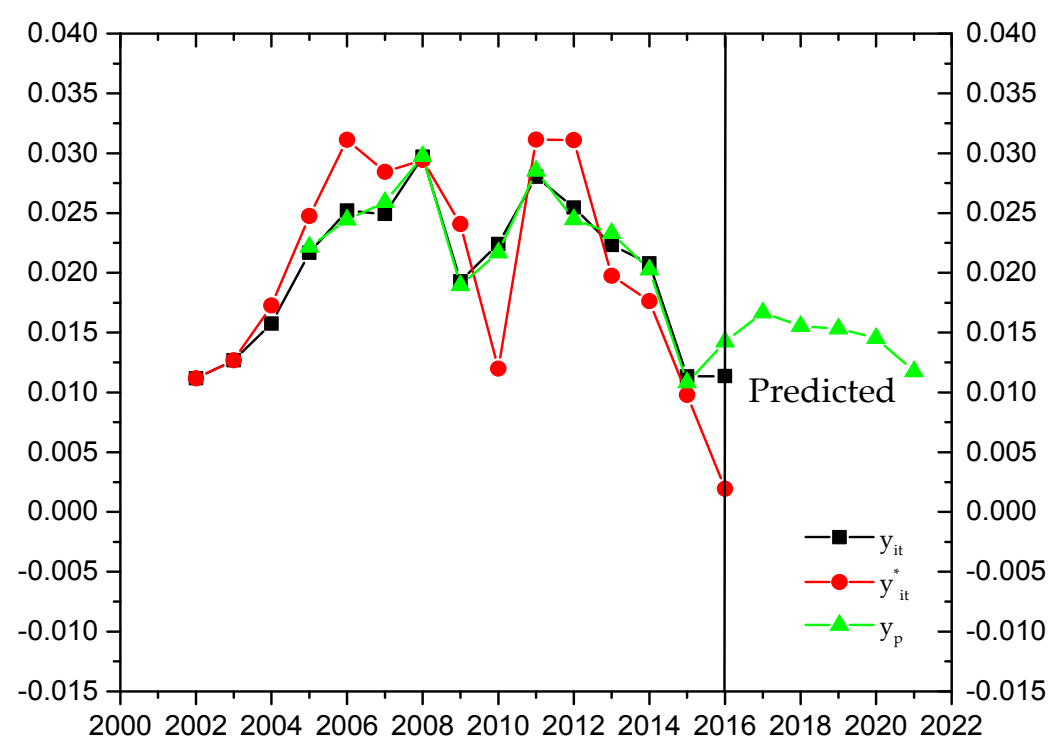

Figure 6. Economic vulnerability index

Overall, seen from the perspective of energy affordability in the next five years, the impact of international energy on China's imports will be reduced, and the energy price will still have space to rise, but the range might not be very wide. China's economic vulnerability index will fall slowly but still be higher than the lowest level in historical record, and the energy affordability will be increasingly enhanced. 


\subsubsection{Environmental Safety Forecasting}

(1) Waste Water Emissions: Figure 7 shows China's waste water emissions were increasing before 2015 and will decline sharply from 2016; the low level of water use efficiency in industrial enterprises leads to consumption of a large amount of water and considerable industrial wastewater discharge, which is likely to make the water shortage even worse.

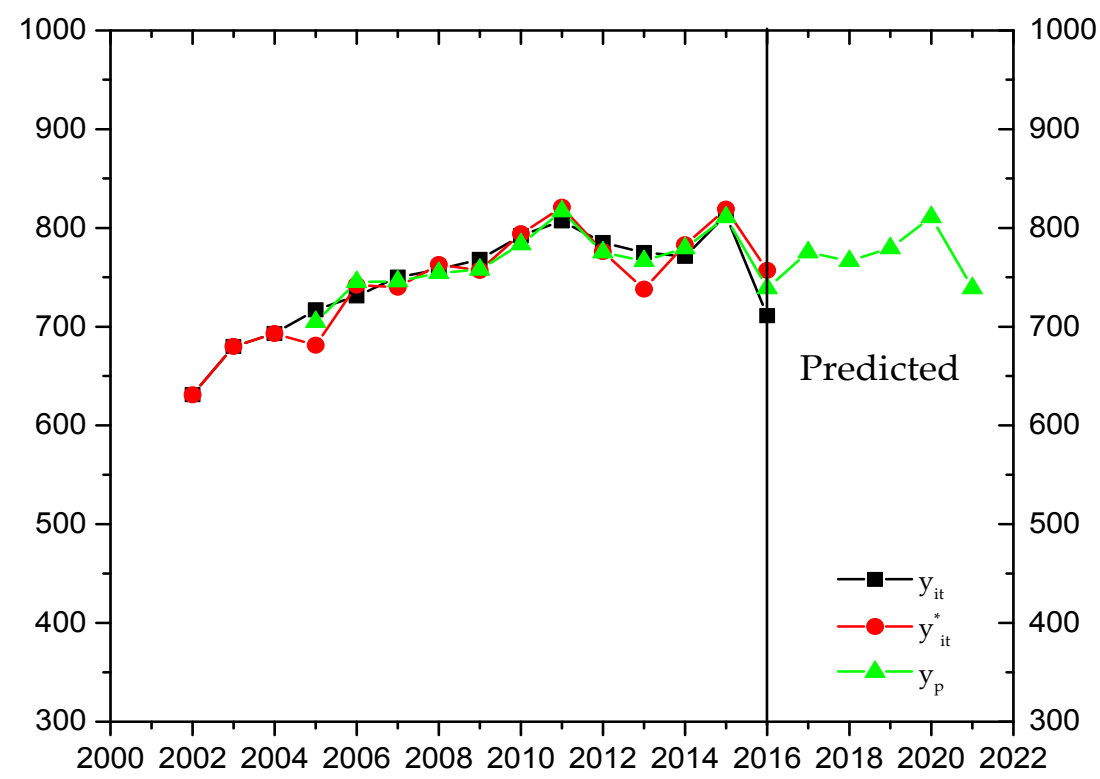

Figure 7. Waste water emissions

The State Council of China issued the "Action plan for the prevention and control of water pollution" in 2015, which was put forward to enhance water use efficiency. The action plan points out that water consumption of industrial value added per 10,000 Yuan in 2020 should be $30 \%$ lower than that of 2013, which will contribute to controlling China's waste water emissions and cause them to decrease during 2017-2021.

(2) $\mathrm{SO}_{2}$ Emissions: Figure 8 displays China's $\mathrm{SO}_{2}$ emissions have been declining since 2006. This figure has fallen to approximately eight megatons in 2016. Since China's economic structure has begun to transform since 2006, the government pays more attention to environmental protection and has strongly supported the development of Green industry as the clean energy industry and has forced dirty industries, such as thermo-electric plants and steel plants, to install desulfurization equipment. The transformation of electric power industry, especially the elimination or retirement of medium and small-sized coal-fired boilers, and the switch from coal to natural gas in winter heating in the countryside have helped reduce China's $\mathrm{SO}_{2}$ emissions. Take Beijing as an example; after implementing these policies, the number of clean air days rose to 226 days in 2017 which is 28 days more than in 2016, and the number of heavy pollution days fell to 23 , which is 16 days less than in 2016. $\mathrm{SO}_{2}$ emissions will decrease during 2017-2021, is predicted. 


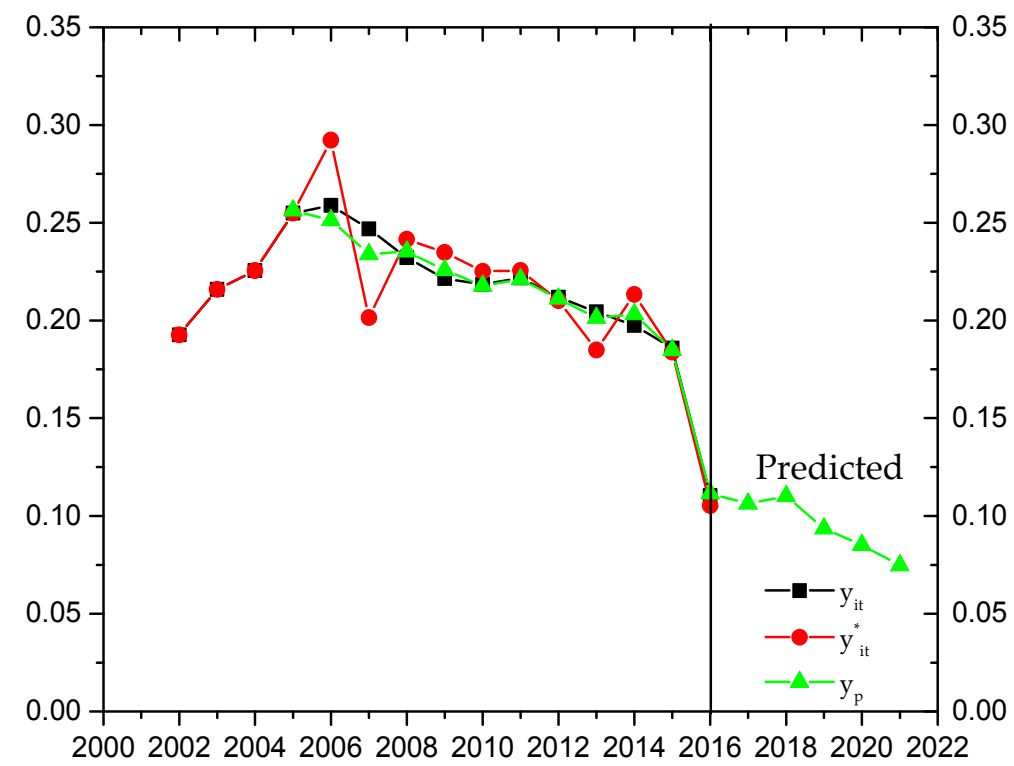

Figure 8. $\mathrm{CO}_{2}$ emissions

(3) NOx Emissions: Figure 9 shows that from 2002 to 2010, there has been an increasing trend in China's NOx emissions followed by a decreasing trend from 2010 that is predicted to continue until 2021. NOx emissions from coal fired power plants in China have been limited since 2011 by new emission standards for air pollutants for thermal power plants. China's government rose to the demand of pollutant emission control for heat-engine plants gradually, the Environmental Protection Agency has repeatedly requested that a fixed Thermal Power Plant flue gas continuous measuring device must be installed on every thermal power plant and provide a smoke pollution emissions standard. Another policy of full implementation of an ultra-low emission and energy saving retrofit plan for coal-fired power plants was put into effect in 2015. These policies have had a significant effect, as can be seen from the observed data. NOx emissions are predicted to decrease during 2017-2021.

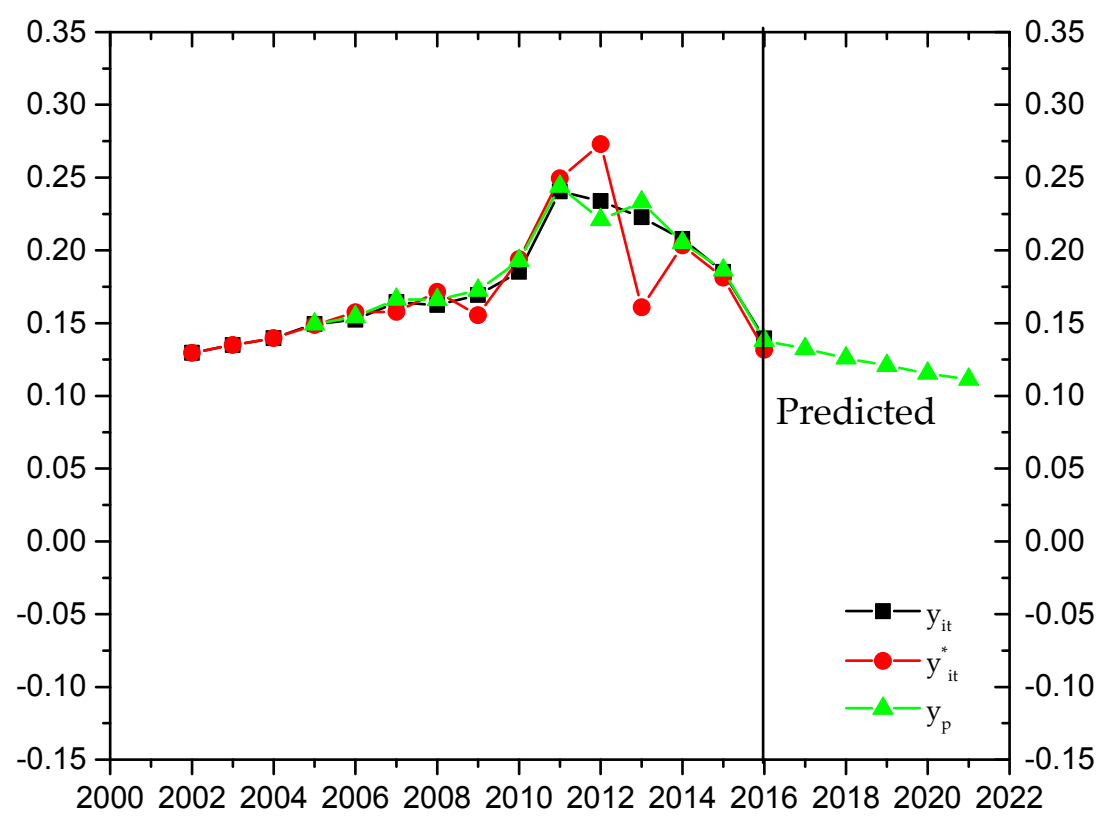

Figure 9. NOx emissions 
(4) $\mathrm{CO}_{2}$ Emissions: Figure 10 shows that China's $\mathrm{CO}_{2}$ emissions increased before 2014 and declined significantly after that, mainly due to the obvious carbon emission reduction effect of the new energy.

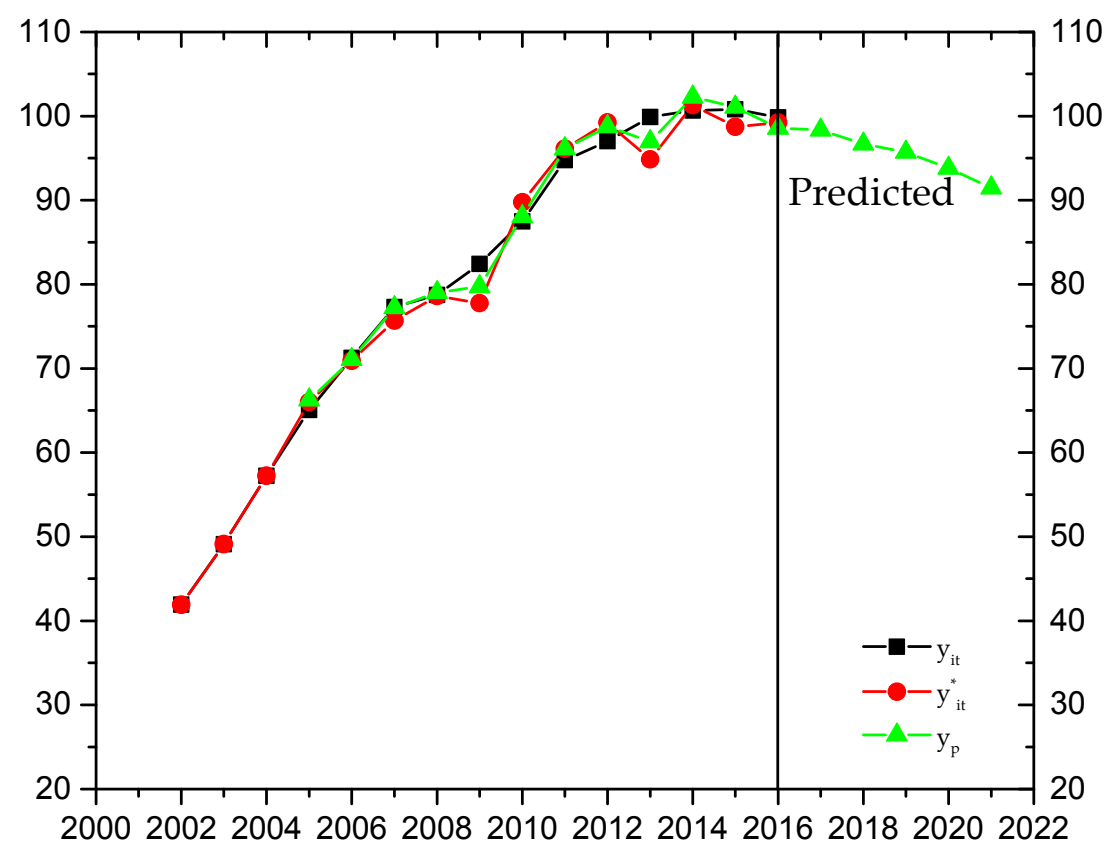

Figure 10. $\mathrm{SO}_{2}$ emissions

According to research by the IEA, renewable energy can contribute up to $35 \%$ of carbon emission reductions. China's new energy power industry has made great achievements since 2007. According to the 13th Five-Year Plan for energy development of China, by 2020 the installed coal-fired power will be controlled to under 11 billion kilowatt hours, and the wind power, nuclear power, and photovoltaic plant installed capacity will reach 210 million kilowatts, 58 million kilowatts, and 250 million kilowatts, respectively. The carbon emission reduction effect of the new energy will be strengthened. China will promote the implementation of these policies over the next five years, and $\mathrm{CO}_{2}$ emissions will be further reduced.

Overall, seen from the environmental dimension, China's policies on control of air and water pollution have had positive effects and provided valuable experience. China will boost the share of the green energy supply and improve the environmental safety of the energy supply to meet the people's desire for a beautiful ecological environment, in the next five years.

\subsubsection{Energy Technology and Efficiency Forecasting}

(1) Clean Power Generation: Figure 11 displays the proportion of clean power generation in power-generation capacity for China has shown a rising trend. The installed proportion of electricity generated by non-fossil fuel was $38.1 \%$ in 2017 , which was the largest in history and was $9.6 \%$ higher than that in 2012. The proportion of clean power generation in power-generation capacity forecasts for the next five years (2017-2021) will be continuously improved because, during the 13th Five-Year Plan of China, various levels of government have taken measures to establish a clean, low-carbon, safe, and efficient energy system. The wind power, nuclear power, and photovoltaic plant installed capacity by 2020 will be greatly enhanced. 


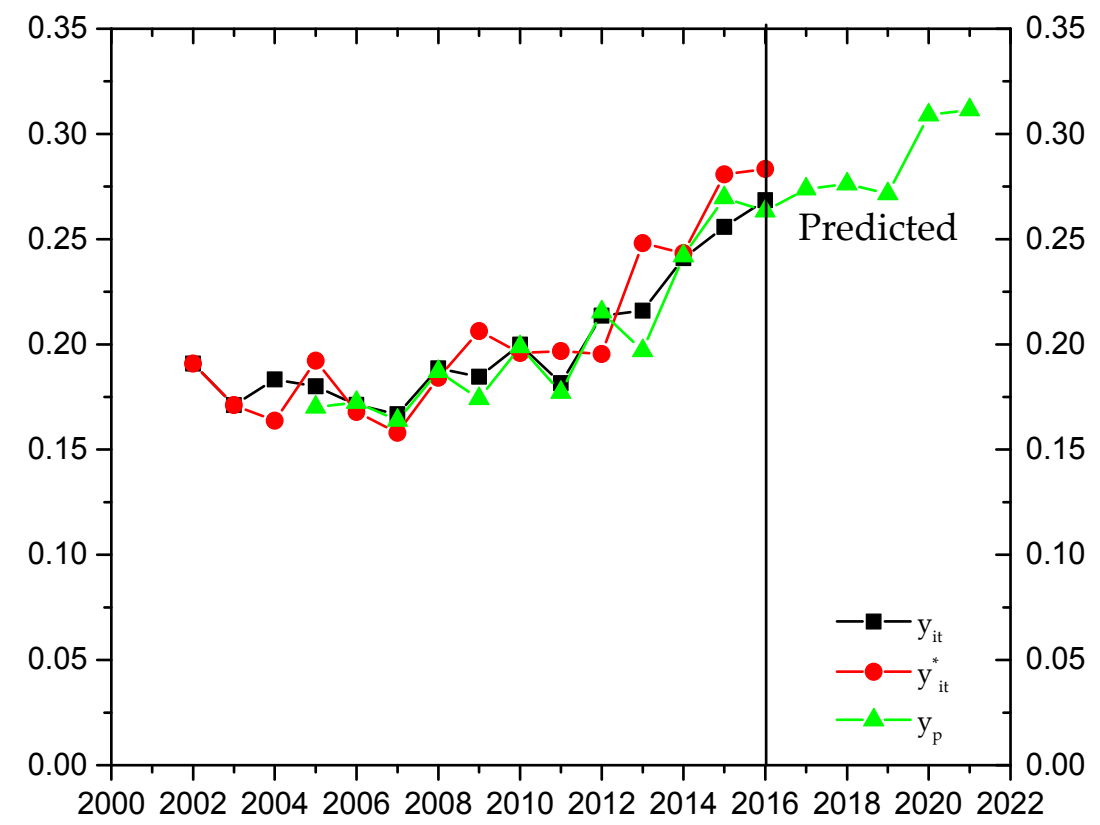

Figure 11. Clean power generation

(2) Domestic Infrastructure: Figure 12 shows that investment in the fixed assets of the energy industry in China demonstrates a rising trend from 2002 to 2021. This is because investment in the fixed assets of the energy industry is important to the improvement of energy output. Since the 1980s, China's energy industries grew rapidly, and investment in the fixed assets of energy industry improved rapidly, rising from 14.19 billion Yuan in 1981 to 33,855.32 billion in 2017. The impacts of large infrastructure projects might be highly variable from a social/cultural point of view, depending on where pipelines and power lines cross and how developers deal with interactions with people living in the area [90].

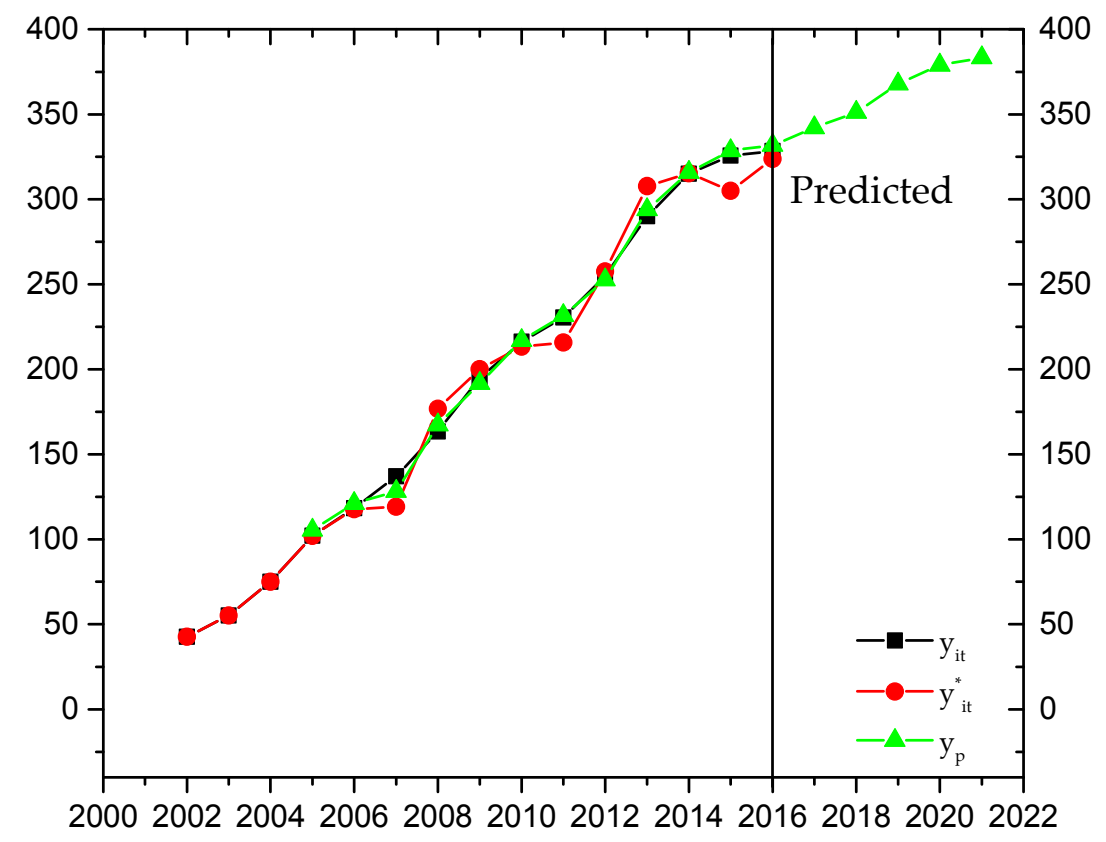

Figure 12. Domestic infrastructure 
(3) Energy Efficiency: Figure 13 demonstrates that the energy efficiency in China has shown a rising trend. Like the latest BP Energy Outlook predicts, from 2010 to 2030, global average energy efficiency will accelerate in nearly all the important countries and regions. Technological advances in China mainly contribute to energy efficiency. Recently, China has put great effort into developing new energy technologies, including reliable and efficient wind power generation systems, which motivate the improvement of energy efficiency and might eventually curb the growth in energy demand.

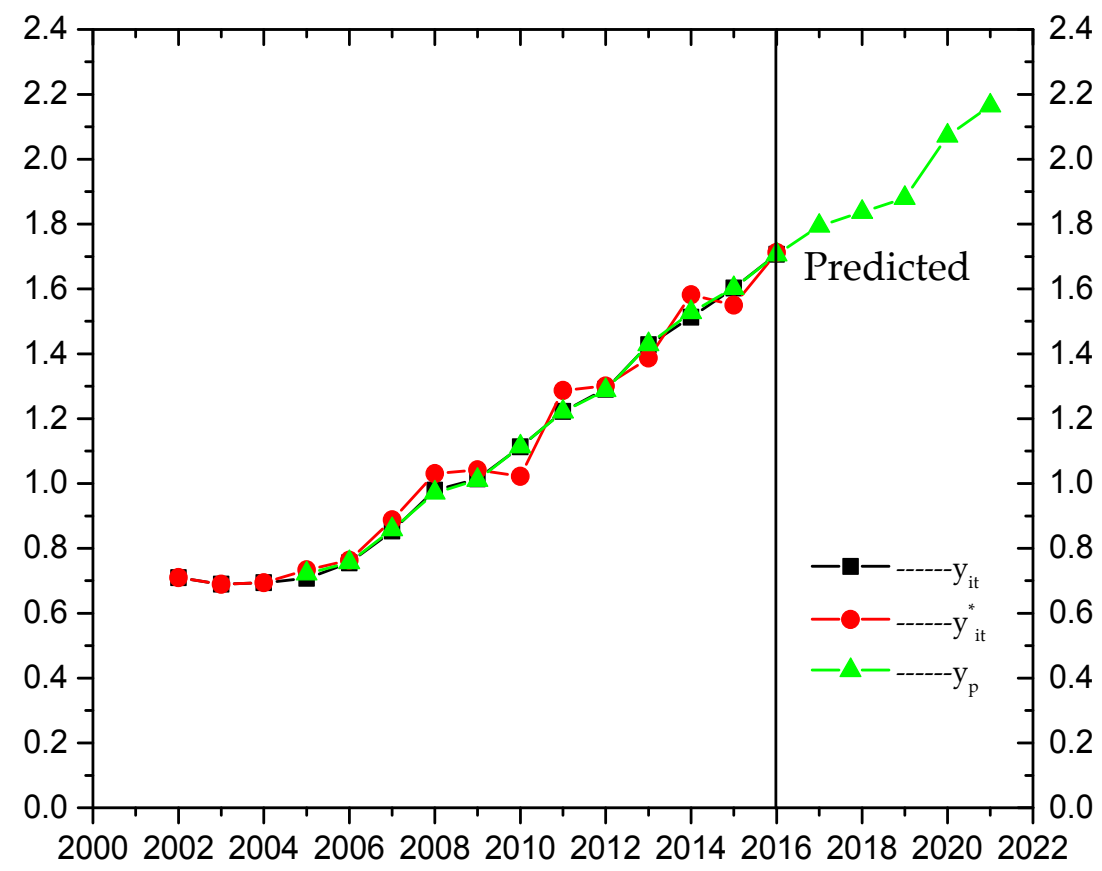

Figure 13. Energy efficiency

Overall, seen from the perspective of energy technology and efficiency, the three indicators all show a rising trend, with energy efficiency showing the fastest increase. The level of scientific and technological progress in China has improved greatly in recent years. New energy technology and energy substitution technology will help to improve energy efficiency and, with the development of clean power generation and an increase in domestic infrastructure, the energy technology and efficiency will be greatly improved, eventually building up an energy supply system that is both clean and highly efficient.

\subsection{Energy Supply Security Index Forecasting Results}

Based on Chinese data from 1990 and 2016, with reference to Equation (5), the authors calculated the weight for each indicator of energy supply security: $w_{i}=(0.1363,0.1278,0.1110,0.0827,0.0611$, $0.0335,0.0231,0.0890,0.0439,0.1044,0.0688,0.1185)$. Indicators in the availability of the energy technology and efficiency dimension had a higher weight-reserve and production ratio (0.1363), production diversity index (0.1278), energy dependence (0.1110), energy efficiency (0.1185), and clean power generation (0.1044) - which indicates the relationships of basic resources to energy supply security, where energy efficiency significantly promoted energy supply security. Indicators in the affordability dimension had a lower weight-energy price index (0.0827), and economic vulnerability index (0.0611) - possibly due to the poor marketization of the energy market and the vulnerability of the economy. Indicators in the environmental dimension had the lowest weight-waste water emissions (0.0890), $\mathrm{SO}_{2}$ emissions (0.0335), NOx emissions (0.0439), and $\mathrm{CO}_{2}$ emissions (0.0335), because scholars and society paid less attention to the environment in the past when considering 
energy supply security. They mostly prefer to get sufficient energy supply at a reasonable price and the impact of the environment on energy supply security oftentimes was overlooked.

Based on Section 5.2, the observed values and the predicted values of each indicator, according to the hybrid forecasting principle for China's energy supply security in Figure 1, the authors calculate the forecasting results of energy supply security ESSI $I_{1}^{*}$ and $E S S I_{2}^{*}$ through the two approaches (Figure 14).

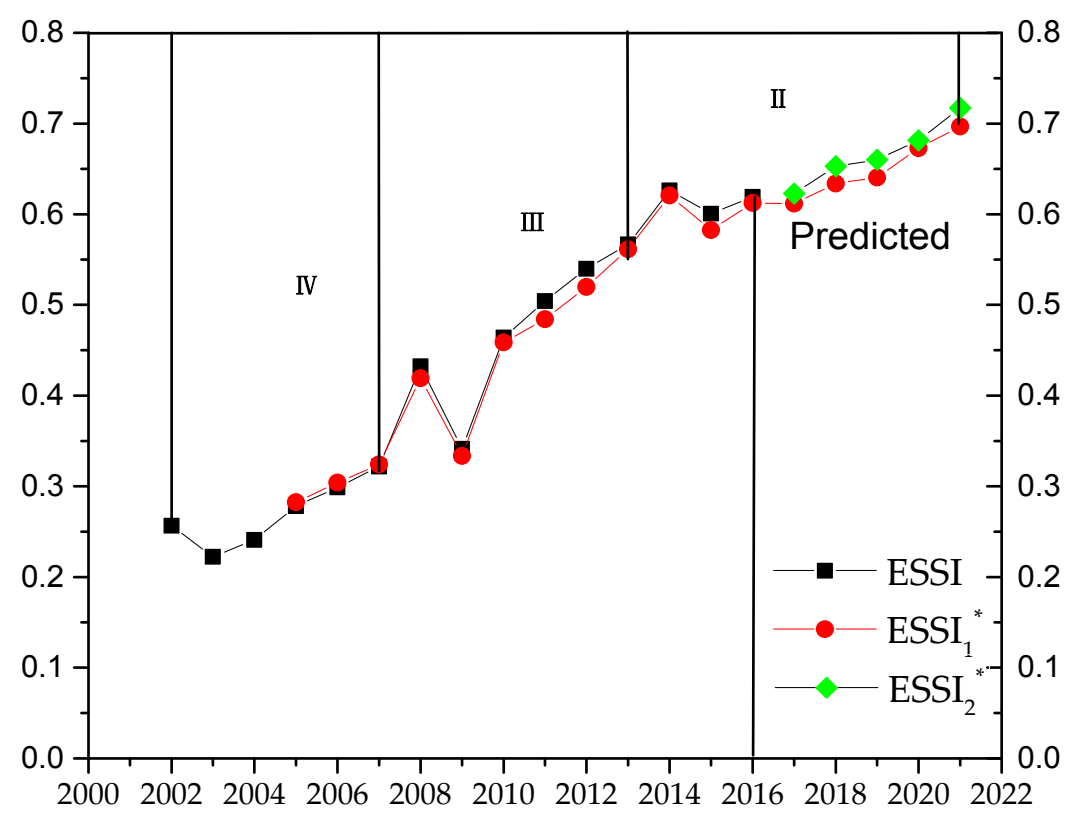

Figure 14. Energy supply security level

Figure 14 displays first, the energy supply security level from 2005 to 2016 forecast by the ARIMA-XGBoost hybrid model is very close to the actual data, which proves that the ARIMA-XGBoost hybrid method is effective in forecasting China's energy supply security level. Second, forecast values of energy supply security level in China derived via the two approaches are quite close to each other and the results show that the ARIMA-XGBoost hybrid method is effective. The predicated value by the first approach ESSI* is also a little lower, as the actual data from 2005 to 2016, predicated by the first approach, is a little lower than itself. Therefore, the forecast value of $E S S I_{2}^{*}$ is more accurate, thus Approach 2 is more suitable for forecasting the energy supply security level of China, and Approach 1 is suitable for forecasting each of its indicators. This scientific discovery provides an effective reference for forecasting the energy supply security level of China.

Seen from the dynamic trend of China's energy supply security (Figure 14), China's energy supply security level continued to rise during the sample period but was not high overall. It was classified into three Grades. China's energy supply security level was lowest before 2007-this was Grade IV—and increased rapidly after 2007; this value improved fastest from 2007 to 2013. This is mainly attributable to government where, from 2007 to 2009, the Chinese government gradually introduced a series of policies to subsidize capital expenditures and support the electricity price to promote the industrial progress of renewable energy. Since these measures alleviated the existing unsafe state, the energy supply security level was place in Grade III from 2007 to 2013. However, the energy supply security level declined obviously in 2009, because, since the financial crisis hit in 2008, energy demand declined quickly leading to an oversupply of energy. Affected by the financial crisis, energy supply in many countries was weakened in 2009, such as in countries of the European South and Ireland [91].

China's energy supply security level increased after 2013 and steadily and climbed to Grade II, but there were some unsafe factors in the energy supply. During the predicted five years from 2017 to 2021, China's energy supply security level will be enhanced further, but it will still be in a 
basic security state of Grade II, mainly related to concrete national conditions of relatively insufficient energy. Coal will still be the main source of energy production and consumption in China for a long time, leading to lower energy supply diversification, higher energy dependency, and serious environmental pollution. China's energy technology is relatively lower, as a developing country, than that of developed countries, therefore, it has a long way to go to become a country with energy supply security.

\section{Conclusions}

Energy supply security is essentially dynamic and contextual. Energy supply security is not only an aspect of energy security, but it also should be a system that can change continually with the development of the times and social progress. China's energy has entered a "new era", and the demand for both quality and quantity of energy supply has increased. Consequently, the energy industry should provide more green energy to satisfy the people's desire for a beautiful ecological environment. Analyzed in detail, with the prospect forecast of China's energy supply security level, corresponds with the times and the laws of scientific research, which also might be of some reference for China and the world while tackling energy supply security and the problem of carbon emission reduction.

Regarding China's development and dynamic growth, the energy supply system is increasingly complex. It is difficult to measure energy supply security, and it is even more difficult to forecast it. It is of great importance to scientifically choose evaluation criteria and prediction methods. Based on previous research, according to the characteristics of energy supply and the social development of China, the authors have put forward a new definition for the energy supply security of China, conceptualizing the energy supply security in twelve indicators in four dimensions: availability, affordability, environment, and energy technology and efficiency. First, the authors evaluated the energy supply security level comprehensively. Then, based on the ARIMA-XGBoost hybrid model, the authors created two approaches for forecasting China's energy supply security. This offered new thinking and methodology for the study of energy supply security.

Comparing the results forecast by the ARIMA model and the ARIMA-XGBoost hybrid model, all the single and hybrid models give highly accurate forecasting results. Since the mean absolute percentage forecasting error results were below $4.5 \%$, the ARIMA-XGBoost hybrid model was more accurate and close to the actual result. This reflects the rationality of the ARIMA-XGBoost hybrid model. Thus, it is reasonable to apply it to forecasting energy supply security, which could provide beneficial reference material for the government department concerned.

Via analyzing the forecasting result of each indicator and the related policies, during 2017-2021, energy affordability, and energy technology and efficiency will be optimized gradually, the environmental pollution due to the energy supply will reduce, the energy supply system will have greater availability, and consumers will get high-quality and less-polluting energy at a more reasonable price. Energy supply security levels in China have stage characteristics and laws that the ESSI can improve about 0.2 every 5 years, but it will not reach to the safety level in a short time owing to the low starting point and multiple types of constraints. Similar to EU countries such as Luxembourg, Malta and Cyprus, countries with high energy dependence and low energy supply diversifications have low energy supply security level. Conversely, countries with high energy supply diversifications, such as Spain and Portugal, have a high energy supply security level. Taking Iceland as an example, it supplies approximately $89 \%$ of its primary energy with renewable resources, mainly geothermal and hydro, it is almost a zero-emissions island, the country has a low risk of energy supply and high security [91]. Looking at the long term, by 2050, China's total energy demand will reach $5.4 \times 10^{9} \mathrm{t} / \mathrm{y}$. However, the domestic annual capacity of production of coal, oil, and natural gas will be $2.5 \times 10^{9} \mathrm{t} / \mathrm{y}$ to $2.7 \times 10^{9} \mathrm{t} / \mathrm{y}, 1 \times 10^{8} \mathrm{t} / \mathrm{y}$ to $2 \times 10^{8} \mathrm{t} / \mathrm{y}$, and $120 \times 10^{9} \mathrm{~m}^{3} / \mathrm{y}$ to $140 \times 10^{9} \mathrm{~m}^{3} / \mathrm{y}$, respectively, so there will be a large supply-demand gap [92].

Renewable energy is an important part of the energy supply system [93]. Presently, the development and utilization of renewable energy is expanding all over the world, thus, its application cost is 
dropping fast. Developing renewable energy has become an important way to promote energy transformation and deal with climate change in many countries, it is also an important measure to improve the energy supply level of China. If Society does not increase the renewable energy supply, China's energy supply security level will be lower. Additional to strengthening energy conservation work, the development and use of renewable energy seems to be an inevitable choice for achieving diversification of energy supply and ensuring China's long-term energy supply security.

To increase the proportion of renewable energy sources such as hydropower, wind, solar, biomass and biofuels, the Chinese government should support the renewable energy development in the following four ways in reference to western experiences, and according to the renewable energy development status in China [94,95]. First, unified planning of the State Grid. Optimizing construction of wind farms and solar power stations for access projects. Second, increase technical support for renewable energy research and development. Chinese government should mobilize adequate resources for renewable energy technologies development, diffusion and transfer, includes: research and development of power grid technology and key technologies for wind power and solar power generation. Third, perfect the tax policy system. Government should introduce external cost collection standard for pollutants and $\mathrm{CO}_{2}$ emission from conventional thermal power plants, imposed levies on the consumption of fossil fuels, to promote the energy saving and emission reduction of fossil energy and encourage renewable energy development. Last, on the premise of guaranteeing energy self-sufficiency, China should also conform to the international situation and carry out extensive energy cooperation with other countries in the world to promote the internationalization of renewable energy.

Author Contributions: All authors contributed equally to this work. J.-S.Z. proposed the original idea, modified and refined the manuscript. P.L. designed this research and wrote this paper. All authors read and approved the final manuscript.

Acknowledgments: This research was supported by the National Natural Science Foundation of China (NSFC) under Grant (No. 71273206, 71704140), the National Soft Science Plan Program (No. 2013GXS4D151) and the Soft Science Research Major Program of Shaanxi Province (No. 2012KR2-01). Philosophy and Social Sciences Prosperous Development Project of Xi'an University of Science and Technology (2018SY03). The authors sincerely thank the anonymous referees as well as the editors.

Conflicts of Interest: The authors declare no conflict of interest.

\section{References}

1. Conti, J.; Holtberg, P.; Diefenderfer, J.; LaRose, A.; Turnure, J.T.; Westfall, L. International Energy Outlook 2016 With Projections to 2040; USDOE Energy Information Administration (EIA): Washington, DC, USA, 2016.

2. Thinnes, B. BP's energy outlook to 2030. Hydrocarbon Process. 2012, 91, 17-19.

3. Suganthi, L.; Samuel, A.A. Energy models for demand forecasting-A review. Renew. Sustain. Energy Rev. 2012, 16, 1223-1240. [CrossRef]

4. Papalexopoulos, A.D.; Hesterberg, T.C. A regression-based approach to short-term system load forecasting. IEEE. Trans. Power Syst. 1990, 5, 1535-1547. [CrossRef]

5. Abdel-Aal, R.; Al-Garni, A. Forecasting monthly electric energy consumption in eastern Saudi Arabia using univariate time-series analysis. Energy 1997, 22, 1059-1069. [CrossRef]

6. Chavez, S.G.; Bernat, J.X.; Coalla, H.L. Forecasting of energy production and consumption in Asturias (northern Spain). Energy 1999, 24, 183-198. [CrossRef]

7. Conejo, A.J.; Plazas, M.A.; Espinola, R.; Molina, A.B. Day-ahead electricity price forecasting using the wavelet transform and ARIMA models. IEEE. Trans. Power Syst. 2005, 20, 1035-1042. [CrossRef]

8. Ediger, V.Ş.; Akar, S.; Uğurlu, B. Forecasting production of fossil fuel sources in Turkey using a comparative regression and ARIMA model. Energy Policy 2006, 34, 3836-3846. [CrossRef]

9. Pappas, S.S.; Ekonomou, L.; Karamousantas, D.C.; Chatzarakis, G.; Katsikas, S.; Liatsis, P. Electricity demand loads modeling using AutoRegressive Moving Average (ARMA) models. Energy 2008, 33, 1353-1360. [CrossRef]

10. Erdogdu, E. Natural gas demand in Turkey. Appl. Energy 2010, 87, 211-219. [CrossRef] 
11. Esen, H.; Ozgen, F.; Esen, M.; Sengur, A. Modelling of a new solar air heater through least-squares support vector machines. Expert Syst. Appl. 2009, 36, 10673-10682. [CrossRef]

12. Pao, H. Forecasting energy consumption in Taiwan using hybrid nonlinear models. Energy 2009, 34, 1438-1446. [CrossRef]

13. Tan, Z.; Zhang, J.; Wang, J.; Xu, J. Day-ahead electricity price forecasting using wavelet transform combined with ARIMA and GARCH models. Appl. Energy 2010, 87, 3606-3610. [CrossRef]

14. Kavousi-Fard, A.; Kavousi-Fard, F. A new hybrid correction method for short-term load forecasting based on ARIMA, SVR and CSA. J. Exp. Theor. Artif. Intell. 2013, 25, 559-574. [CrossRef]

15. Yan, X.; Chowdhury, N.A. Mid-term electricity market clearing price forecasting utilizing hybrid support vector machine and auto-regressive moving average with external input. Int. J. Electr. Power 2014, 63, 64-70. [CrossRef]

16. Azadeh, A.; Asadzadeh, S.; Mirseraji, G.; Saberi, M. An emotional learning-neuro-fuzzy inference approach for optimum training and forecasting of gas consumption estimation models with cognitive data. Technol. Forecast. Soc. Chang. 2015, 91, 47-63. [CrossRef]

17. Yuan, C.; Liu, S.; Fang, Z. Comparison of China's primary energy consumption forecasting by using ARIMA (the autoregressive integrated moving average) model and GM (1, 1) model. Energy 2016, 100, 384-390. [CrossRef]

18. Niu, D.; Liang, Y.; Hong, W.C. Wind Speed Forecasting Based on EMD and GRNN Optimized by FOA. Energies 2017, 10, 2001. [CrossRef]

19. Chen, T.; Guestrin, C. Xgboost: A scalable tree boosting system. In Proceedings of the 22nd ACM Sigkdd International Conference on Knowledge Discovery and Data Mining, San Francisco, CA, USA, 13-17 August 2016; pp. 785-794.

20. Lei, T.; Chen, F.; Liu, H.; Sun, H.; Kang, Y.; Li, D.; Li, Y.; Hou, T. ADMET evaluation in drug discovery. Part 17: Development of quantitative and qualitative prediction models for chemical-induced respiratory toxicity. Mol. Pharm. 2017, 14, 2407-2421. [CrossRef] [PubMed]

21. Torres-Barrán, A.; Alonso, Á.; Dorronsoro, J.R. Regression tree ensembles for wind energy and solar radiation prediction. Neurocomputing 2017. [CrossRef]

22. Guangye, L. I. Short-term electricity load forecasting based on the xgboost algorithm. Smart Grid 2017, 7, 274-285.

23. Barak, S.; Sadegh, S.S. Forecasting energy consumption using ensemble ARIMA-ANFIS hybrid algorithm. Int. J. Electr. Power 2016, 82, 92-104. [CrossRef]

24. Lin, C.H.; Shen, D.Y.; Chen, Y.J. Secret:a selective error correction framework for refresh energy reduction in DRAMs. Trans. Archit. Code Optim. 2015, 12, 67-74.

25. Zhang, J.; Qi, Q. Reviews on supply security of China's vital energy under uncertainties. Resour. Ind. 2013, 15, 11-18.

26. Pin, L. Study on the influencing factors of energy supply security in China. J. Xi'an Univ. Mech. Sci. Technol. 2018, 38, 403-410.

27. Ketting, N.G. Towards a sustainable energy future. Energy Policy 1995, 23, 637-638. [CrossRef]

28. Nakicenovic, N. World Energy Outlook 2007: China and India insights. IEA 2007, 1, 3.

29. Eng, G. Energy Security Initiative: Some Aspects of Oil Security; Asia Pacific Energy Research Centre: Tokyo, Japan, 2003.

30. Yergin, D. Energy Security in the 1990s. Foreign Affairs 1988, 67, 110-132. [CrossRef]

31. Van, D.L.C.; Amineh, M.P.; Correljé, A. Study on Energy Supply Security and Geopolitics; The Netherlands Institute of International Relations: Hague, The Netherlands, 2004.

32. Sovacool, B.K.; Mukherjee, I.; Drupady, I.M.; D'Agostino, A.L. Evaluating energy security performance from 1990 to 2010 for eighteen countries. Energy 2011, 36, 5846-5853. [CrossRef]

33. Ren, J.; Sovacool, B.K. Enhancing China's energy security: Determining influential factors and effective strategic measures. Energy Convers. Manag. 2014, 88, 589-597. [CrossRef]

34. Winzer, C. Conceptualizing energy security. Energy Policy 2012, 46, 36-48. [CrossRef]

35. Von, H.D. Energy security (East Asia). Berks. Encycl. Sustain. 2012, 143-150.

36. Ang, B.W.; Choong, W.; Ng, T. Energy security: Definitions, dimensions and indexes. Sustain. Energy Rev. 2015, 42, 1077-1093. [CrossRef] 
37. Johansson, T.B.; Patwardhan, A.; Nakicenovic, N.; Gomez, E.L. Global Energy Assessment: Towards a Sustainable Future; Cambridge University Press: Cambridge, UK, 2012; Volume 31, pp. 9-17.

38. Zeng, L.J.; Zhao, L.J.; Wang, Q.; Wang, B.C.; Xie, Y.J.; Ma, Y.; Cui, W. Modeling Interprovincial Cooperative Energy Saving in China: An Electricity Utilization Perspective. Energies 2018, 11, 241. [CrossRef]

39. Fang, D.; Shi, S.; Yu, Q. Evaluation of sustainable energy security and an empirical analysis of china. Sustainability 2018, 10, 1685. [CrossRef]

40. Radovanović, M.; Filipović, S.; Pavlović, D. Energy security measurement-A sustainable approach. Renew. Sustain. Energy Rev. 2017, 68, 1020-1032. [CrossRef]

41. Hotelling, H. The Economics of Exhaustible Resources. Bull. Math. Biol. 1931, 39, 137-175. [CrossRef]

42. Romerio, F.; Ferraz, C. Security of supply and renewable energy in the light of the opening of electricity markets to competition. In Proceedings of the Investing for Sustainability-5th SESSA Conference, Madrid, Spain, 19-20 May 2005.

43. Stefanova, B. European Strategies for Energy Security in the Natural Gas Market. J. Strateg. Secur. $2012,5,51$. [CrossRef]

44. Mansson, A.; Johansson, B.; Nilsson, L.J. Assessing energy security: An overview of commonly used methodologies. Energy 2014, 73, 1-14. [CrossRef]

45. Davis, M.; Piontkivsky, R.; Pindyuk, O. Ukraine: The Impact of Higher Natural Gas and Oil Prices; The World Bank: Washington, DC, USA, 2005; p. 6.

46. Wirl, F. The exploitation of fossil fuels under the threat of global warming and carbon taxes: A dynamic game approach. Environ. Resour. Econ. 1995, 5, 333-352. [CrossRef]

47. Nunes, P.D.S. Towards a European strategy for the security of energy supply. VGB PowerTech 2002, 82, 27-29.

48. Harris, D.V.P. Mineral resource stocks and information. Handb. Nat. Resour. Energy Econ. 2006, 3, 1011-1076.

49. Dorian, J.P.; Franssen, H.T.; Simbeck, D.R. Global challenges in energy. Energy Policy 2006, 34, $1984-1991$. [CrossRef]

50. Turton, H.; Barreto, L. Long-term security of energy supply and climate change. Energy Policy 2006, 34, 2232-2250. [CrossRef]

51. Kemmler, A.; Spreng, D. Energy indicators for tracking sustainability in developing countries. Energy Policy 2007, 35, 2466-2480. [CrossRef]

52. Hughes, L. The four 'R's of energy security. Energy Policy 2009, 37, 2459-2461. [CrossRef]

53. Coq, C.L.; Paltseva, E. Measuring the security of external energy supply in the European Union. Energy Policy 2009, 37, 4474-4481. [CrossRef]

54. Bambawale, M.J.; Sovacool, B.K. China's energy security: The perspective of energy users. Appl. Energy 2011, 88, 1949-1956. [CrossRef]

55. Hippel, D. v.; Suzuki, T.; Williams, J.H.; Savage, T.; Hayes, P. Energy security and sustainability in Northeast Asia. Energy Policy 2011, 39, 6719-6730. [CrossRef]

56. Sovacool, B.K.; Mukherjee, I. Conceptualizing and measuring energy security: A synthesized approach. Energy 2011, 36, 5343-5355. [CrossRef]

57. Geng, J.B.; Ji, Q. Multi-perspective analysis of China's energy supply security. Energy 2014, 64, 541-550. [CrossRef]

58. Zhang, J.; Liu, C.; Zhang, W.; Yuan, X. On comprehensive evaluation of safe, green and efficient development of coal resources. China Coal 2014, 01, 15-19.

59. Ren, J.; Sovacool, B.K. Quantifying, measuring, and strategizing energy security: Determining the most meaningful dimensions and metrics. Energy 2014, 76, 838-849. [CrossRef]

60. Brown, M.A.; Wang, Y.; Sovacool, B.K.; D’Agostino, A.L. Forty years of energy security trends: A comparative assessment of 22 industrialized countries. Energy Res. Soc. Sci. 2014, 4, 64-77. [CrossRef]

61. Ren, J.; Sovacool, B.K. Prioritizing low-carbon energy sources to enhance China's energy security. Energy Convers. Manag. 2015, 92, 129-136. [CrossRef]

62. Narula, K.; Reddy, B.S.; Pachauri, S. Sustainable Energy Security for India: An assessment of energy demand sub-system. Appl. Energy 2017, 186, 126-139. [CrossRef]

63. Vivoda, V. Evaluating energy security in the Asia-Pacific region: A novel methodological approach. Energy Policy 2010, 38, 5258-5263. [CrossRef] 
64. Lucas, J.N.V.; Francés, G.E.; González, E.S.M.; Kazmerski, L. Energy security and renewable energy deployment in the EU: Liaisons Dangereuses or Virtuous Circle? Renew. Sustain. Energy Rev. 2016, 62, 1032-1046. [CrossRef]

65. Erahman, Q.F.; Purwanto, W.W.; Sudibandriyo, M.; Hidayatno, A. An assessment of Indonesia's energy security index and comparison with seventy countries. Energy 2016, 111, 364-376. [CrossRef]

66. Li, Y.; Shi, X.; Yao, L. Evaluating energy security of resource-poor economies: A modified principle component analysis approach. Energy Econ. 2016, 58, 211-221. [CrossRef]

67. Cohen, G.; Joutz, F.; Loungani, P. Measuring energy security: Trends in the diversification of oil and natural gas supplies. Energy Policy 2011, 39, 4860-4869. [CrossRef]

68. Pavlović, D.; Banovac, E.; Vištica, N. Defining a composite index for measuring natural gas supply security-the croatian gas market case. Energy Policy 2018, 114, 30-38. [CrossRef]

69. Duenas, P.; Ramos, A.; Tapia, A. K.; Olmos, L.; Rivier, M.; Pérez, A.J.I. Security of supply in a carbon-free electric power system: The case of Iceland. Appl. Energy 2018, 212, 443-454. [CrossRef]

70. Mohsin, M.; Zhou, P.; Iqbal, N.; Shah, S.A.A. Assessing Oil Supply Security of South Asia. Energy 2018, 155, 438-447. [CrossRef]

71. Castro, M. Assessing the risk profile to security of supply in the electricity market of Great Britain. Energy Policy 2017, 111, 148-156. [CrossRef]

72. Ang, B.W.; Choong, W.L.; Ng, T.S. A framework for evaluating Singapore's energy security. Appl. Energy 2015, 148, 314-325. [CrossRef]

73. Narula, K.; Reddy, B.S. Three blind men and an elephant: The case of energy indices to measure energy security and energy sustainability. Energy 2015, 80, 148-158. [CrossRef]

74. Jonsson, D.K.; Johansson, B.; Månsson, A.; Nilsson, L.J.; Nilsson, M.; Sonnsjö, H. Energy security matters in the EU Energy Roadmap. Energy Strateg. Rev. 2015, 6, 48-56. [CrossRef]

75. Li, P.; Zhang, J.; Xu, J. A Dynamic Approach to Measuring China's Provincial Energy Supply Security along "the Belt and Road". Math. Probl. Eng. 2018. [CrossRef]

76. Hippela, D.V.; Savagea, T.; Hayesa, P. Introduction to the Asian Energy Security project: Project organization and methodologies. Energy Policy 2011, 39, 6712-6718. [CrossRef]

77. Augutis, J.; Krikštolaitis, R.; Pečiulytè, S.; Žutautaitè, I. Dynamic model based on Bayesian method for energy security assessment. Energy. Convers. Manag. 2015, 101, 66-72. [CrossRef]

78. Inglesi, L. R.; Pouris, A. Energy efficiency in South Africa: A decomposition exercise. Energy 2012, 42, 113-120. [CrossRef]

79. Narula, K.; Reddy, B.S.; Pachauri, S. Sustainable Energy Security for India: An assessment of energy supply sub-system. Energy Policy 2017, 103, 127-144. [CrossRef]

80. Ding, L.; Shao, Z.; Zhang, H.; Xu, C.; Wu, D.A. Comprehensive Evaluation of Urban Sustainable Development in China Based on the TOPSIS-Entropy Method. Sustainability 2016, 8, 746. [CrossRef]

81. Zhou, P.; Ang, B.W.; Poh, K.L. Comparing aggregating methods for constructing the composite environmental index: An objective measure. Ecol. Econ. 2006, 59, 305-311. [CrossRef]

82. Liu, F.; Zhao, S.; Weng, M.; Liu, Y. Fire risk assessment for large-scale commercial buildings based on structure entropy weight method. Safety Sci. 2017, 94, 26-40. [CrossRef]

83. Zhang, G.P. Time series forecasting using a hybrid ARIMA and neural network model. Neurocomputing 2003, 50, 159-175. [CrossRef]

84. Valenzuela, O.; Rojas, I.; Rojas, F. Hybridization of intelligent techniques and ARIMA models for time series prediction. Fuzzy Set Syst. 2008, 159, 821-845.

85. Maatallah, O.A.; Achuthan, A.; Janoyan, K. Recursive wind speed forecasting based on Hammerstein Auto-Regressive model. Appl. Energy 2015, 145, 191-197. [CrossRef]

86. Torlay, L.; Perrone-Bertolotti, M.; Thomas, E.; Baciu, M. Machine learning-XGBoost analysis of language networks to classify patients with epilepsy. Brain Inform. 2017, 4, 159-169. [CrossRef] [PubMed]

87. Zheng, H.; Yuan, J.; Chen, L. Short-Term Load Forecasting Using EMD-LSTM Neural Networks with a Xgboost Algorithm for Feature Importance Evaluation. Energies 2017, 10, 1168. [CrossRef]

88. Fan, J.; Wang, X.; Wu, L.; Zhou, H.; Zhang, F.; Yu, X.; Lu, X.; Xiang, Y. Comparison of Support Vector Machine and Extreme Gradient Boosting for predicting daily global solar radiation using temperature and precipitation in humid subtropical climates: A case study in China. Energy Convers. Manag. 2018, 164, 102-111. [CrossRef] 
89. Pan, L.; Liu, P.; Li, Z. A system dynamic analysis of China's oil supply chain: Over-capacity and energy security issues. Appl. Energy 2017, 188, 508-520. [CrossRef]

90. Hippel, D.V.; Gulidov, R.; Kalashnikov, V.; Hayes, P. Northeast Asia regional energy infrastructure proposals. Energy Policy 2011, 39, 6855-6866. [CrossRef]

91. Chalvatzis, K.J.; Ioannidis, A. Energy supply security in the EU: Benchmarking diversity and dependence of primary energy. Appl. Energy 2017, 207, 465-476. [CrossRef]

92. Zhou, N.; Fridley, D.; Khanna, N.Z.; Ke, J.; McNeil, M.; Levine, M. China's energy and emissions outlook to 2050: Perspectives from bottom-up energy end-use model. Energy Policy 2013, 53, 51-62. [CrossRef]

93. Kiriyama, E.; Kajikawa, Y. A multilayered analysis of energy security research and the energy supply process. Appl. Energy 2014, 123, 415-423. [CrossRef]

94. Sovacool, B.K.; Walter, G. Major hydropower states, sustainable development, and energy security: Insights from a preliminary cross-comparative assessment. Energy 2018, 142, 1074-1082. [CrossRef]

95. Ma, L.W.; Liu, P.; Fu, F.; Li, Z.; Ni, W.D. Integrated energy strategy for the sustainable development of China. Energy 2011, 36, 1143-1154. [CrossRef]

(C) 2018 by the authors. Licensee MDPI, Basel, Switzerland. This article is an open access article distributed under the terms and conditions of the Creative Commons Attribution (CC BY) license (http://creativecommons.org/licenses/by/4.0/). 